The Mission and Technology of a Gas Dynamic Trap Neutron Source for Fusion Material and Component Testing and Qualification

A. Ivanov, J. Kulcinski, A. Molvik, D. Ryutov, J. Santarius, T. Simonen, B. D. Wirth, A. Ying

December 1, 2009

Fusion Science \& Technology 
This document was prepared as an account of work sponsored by an agency of the United States government. Neither the United States government nor Lawrence Livermore National Security, LLC, nor any of their employees makes any warranty, expressed or implied, or assumes any legal liability or responsibility for the accuracy, completeness, or usefulness of any information, apparatus, product, or process disclosed, or represents that its use would not infringe privately owned rights. Reference herein to any specific commercial product, process, or service by trade name, trademark, manufacturer, or otherwise does not necessarily constitute or imply its endorsement, recommendation, or favoring by the United States government or Lawrence Livermore National Security, LLC. The views and opinions of authors expressed herein do not necessarily state or reflect those of the United States government or Lawrence Livermore National Security, LLC, and shall not be used for advertising or product endorsement purposes. 


\section{The Mission and Technology of a Gas Dynamic Trap Neutron Source for Fusion Material and Component Testing and Qualification}

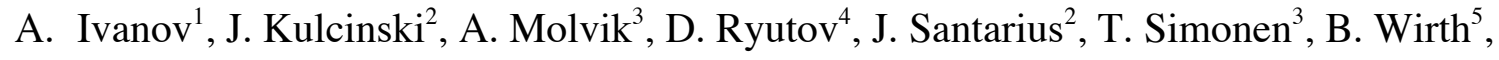
A. Ying $^{6}$

${ }^{1}$ Budker Institute of Nuclear Physics, Prospeckt Lavrent'eva 11, Novosibirsk 630090, Russia

${ }^{2}$ Dept. of Nuclear Engineering, Univ. Wisconsin, Madison, WI 53706

${ }^{3}$ Oak Ridge Associated Universities, P.O. Box 117, MS-17, Oak Ridge, TN 37831-0117

${ }^{4}$ Lawrence Livermore National Laboratory, Livermore, CA 94550

${ }^{5}$ Dept. of Nuclear Engineering, University of California, Berkeley, CA 94709

${ }^{6}$ Mechanical and Aerospace Engineering, University of California, Box 951597, 43-133

Engr IV, Los Angeles, CA 90095-1597

Text $\quad$ Pages 1-36

References (69) Pages 37-45

Footnotes (2) Pages 46

Tables (3) $\quad$ Pages 47-49

Figures (15) Pages 50-65

Figure captions $\quad$ Pages 68-70

Appendix $\quad$ Pages 71-81

Mail proofs and page charge invoice to

Arthur Molvik, 678 Hayes Ave., Livermore, CA 94550

(925) 373-8437, akmolvik@comcast.net 


\title{
The Mission and Technology of a Gas Dynamic Trap Neutron Source for Fusion Material and Component Testing and Qualification
}

\author{
B. Ivanov ${ }^{1}$, J. Kulcinski ${ }^{2}$, A. Molvik ${ }^{3}$, D. Ryutov ${ }^{4}$, J. Santarius ${ }^{2}$, T. Simonen ${ }^{3}$, B. Wirth ,
}

\section{A. Ying ${ }^{6}$}

\begin{abstract}
The successful operation (with $\beta \leq 60 \%$, classical ions and electrons with $\mathrm{Te}=250 \mathrm{eV}$ ) of the Gas Dynamic Trap (GDT) device at the Budker Institute of Nuclear Physics (BINP) in Novosibirsk, Russia, extrapolates to a $2 \mathrm{MW} / \mathrm{m}^{2}$ Dynamic Trap Neutron Source (DTNS), which burns only $\sim 100 \mathrm{~g}$ of tritium per full power year. The DTNS has no serious physics, engineering, or technology obstacles; the extension of neutral beam lines to steady state can use demonstrated engineering; and it supports near-term tokamaks and volume neutron sources. The DTNS provides a neutron spectrum similar to that of ITER and satisfies the missions specified by the materials community to test fusion materials (listed as one of the top grand challenges for engineering in the $21^{\text {st }}$ century by the U.S. National Academy of Engineering) and subcomponents (including tritium-breeding blankets) needed to construct DEMO. The DTNS could serve as the first Fusion Nuclear Science Facility (FNSF), called for by ReNeW, and could provide the data necessary for licensing subsequent FSNFs.
\end{abstract}




\section{INTRODUCTION}

The gas dynamic trap DT Neutron Source (DTNS) concept is being developed at the Budker Institute of Nuclear Physics (BINP) in Novosibirsk, Russia ${ }^{1-7}$. The DTNS may be described as a line source of neutrons, in contrast to a spallation or a D-Lithium source with neutrons beaming from a point, or a tokamak volume source. The DTNS is a neutral beam driven linear plasma system with magnetic mirrors to confine the energetic deuterium and tritium beam injected ions, which produce the $14 \mathrm{MeV}$ neutrons. The hot ions are imbedded in warm-background plasma, which traps the neutral atoms and provides both MHD and micro stability to the plasma. The $14 \mathrm{MeV}$ neutron flux ranges typically at the level of 1 to $4 \mathrm{MW} / \mathrm{m}^{2}$.

The DTNS concept has similarities to magnetic mirror plasma concepts investigated previously but has several stark differences:

1. The magnetic mirror geometry is created with circular coils only so the magnetic field topology is axisymmetric, rather than minimum-B. This simplifies construction and maintenance of the DTNS devices. Since the magnetic field topology is axisymmetric there is no resonant particle transport or neoclassical radial transport that is associated with minimum-B mirror systems and toroidal systems.

2. Thermal Barriers are not needed in the DTNS concept as in some previous mirror reactor systems. Also no tandem mirror end plugs are employed in the version considered here. The absence of these elements reduces the number of auxiliary systems needed and also simplifies the physics.

3. The DTNS concept operates with relatively low electron temperature $(\sim 1 \%$ of the beam injection energy compared to higher ratios $(\sim 10 \%)$ in previous mirror reactor 
designs. While the lower electron temperatures result in faster electron drag cooling of the energetic ions, the plasma potential is lower so the warm-ion energydistribution is nearly Maxwellian and thereby suppresses the drive for Drift Cyclotron Loss Cone (DCLC) micro-instabilities that would be present with higher plasma potentials.

4. The DTNS magnetic field can be tuned to vary the intensity and uniformity of the neutron flux as desired.

5. The tritium requirement is modest ( $\sim 0.1 \mathrm{~kg}$ per full power year), because the test area $\left(\sim 2 \mathrm{~m}^{2}\right)$ and test volume ( 100 liters) are modest. This allows the tritium to be purchased, rather than requiring a tritium-breeding blanket (which must work on larger devices to provide the fueling required for operation).

6. The neutral beams and gas or pellet fueling operate on a mix of deuterium and tritium (DT), removing the need for an expensive and complex tritium system to separate tritium from deuterium.

Extensive engineering concept and design work has been completed by the BINP in Novosibirsk in collaboration with the Efremov Institute in St. Petersburg, KFA in Karlsruhe, Germany; FDR in Dresden, Germany; ITP Snezhinsk, Russia; EURATOM. Fracati, Italy; etc. [e.g. Ref. 3]. An earlier design was based on superconducting coils augmented at the mirrors with a copper insert coil. A later design employed all superconducting coils in order to reduce the electrical power requirements. Our workshop was largely based on publications from these designs.

While the DTNS concept is not new, the recent achievement of $60 \%$ central beta in the GDT linear axisymmetric magnet configuration and electron temperatures exceeding 
$200 \mathrm{eV}$ provide key verification of the concept ${ }^{5-7}$. The recent results provide the basis to extrapolate to a higher energy hydrogen prototype and then to a complete DT neutron source.

The key conclusions of the workshop are:

1. The DTNS design satisfies the missions specified by the materials community to test fusion materials (listed as one of the top grand challenges for engineering in the $21^{\text {st }}$ century by the U.S. National Academy of Engineering) and subcomponents needed to construct DEMO.

2. There are no serious Technology or Engineering obstacles to construct DTNS, although:

a. Neutral beam lines must be extended to steady state, as is also needed for tokamak systems. The technologies to do this are developed, as will be discussed.

b. Recent developments in magnet technology could allow somewhat higher mirror fields to improve DTNS efficiency.

c. Optimization of warm plasma scenarios would reduce tritium, and other gas processing, system requirements.

3. The DTNS supports the magnetic-fusion energy science program and enables the increased materials and engineering science needed for an energy program.

a. It could function as the first Fusion Nuclear Science Facility (FNSF) and could develop the materials, and components (including tritium-breeding blanket modules) database necessary for building and licensing subsequent FNSFs. 
b. It could develop the steady-state neutral beam injectors, beam dumps, and pumping also needed on tokamak-based neutron sources, such as FDF and CTF as well as current experiments such as EAST, KSTAR, and JT-60SA. Radiation damage and activation are reduced by injecting into a lower neutron producing volume, so injectors should last longer on the DTNS. If radiation damage proves to be an issue, the DTNS will be an effective test bed for developing longer lasting injectors for the subsequent tokamak neutron sources.

c. Provides facilities for both materials development and subcomponent development and testing, with neutron spectrum similar to ITER to get activation right as well as $\mathrm{H}$ and $\mathrm{He}$ generation ratios and blistering. Provides the data necessary for licensing a Fusion Nuclear Science Facility.

d. Provides a superior facility for developing tritium-breeding blankets, as they can fail to breed without compromising the DTNS mission.

In the following Section II we describe the mechanisms by which radiation damages materials, present criteria for selection of materials and the design window, discuss the current choices of reduced-activation materials, and discuss the requirements of a neutron source for evaluation and qualification of materials for fusion systems. Section III contains a description of component testing that is needed and could be carried out in DTNS. Section IV describes past mirror-based neutron source designs. Section V describes the DTNS engineering concept that satisfies the materials and component testing requirements, as well as the technical readiness of key systems: steady-state 
neutral beams, magnets, and tritium processing. Section VI discusses where we go from here. Section VII lists the references, and the Appendix gives additional bibliography primarily on the Gas Dynamic Trap.

\section{STRUCTURAL MATERIALS TESTING FOR THE FUSION ENVIRONMENT ${ }^{b}$}

\section{II.A. Mechanisms for material damage}

Fusion power plant first wall and blanket systems arguably represent the single greatest structural materials challenge of all time. Even moderate performance goals will place totally unprecedented and unexplored demands on materials and structures. The materials-structures demands for fusion energy far exceed any experienced by current technology, including light water reactors, which have themselves suffered many materials degradation problems ${ }^{8,9}$. Indeed, the United States National Academy of Engineering has recently ranked the quest for fusion as one of the top grand challenges for engineering in the $21^{\text {st }}$ Century ${ }^{10}$.

Exposure to high-energy radiation severely damages the microstructure of materials by violently displacing atoms from their lattice sites many times and creating damaging concentrations of helium and hydrogen. The resulting microstructural and damage evolutions cause profound macroscopic property changes that severely degrade the performance and lifetime limits of first wall components ${ }^{11-15}$. As reviewed recently by Zinkle $^{14}$, the observed property changes of irradiated materials depend on the irradiation 
temperature and other environmental variables and have been called the 'scourges of irradiation', and include irradiation hardening and embrittlement, phase and dimensional instability and He embrittlement.

The effect of irradiation on materials microstructure and properties is a classic example of an inherently multiscale phenomenon. Pertinent processes range from the atomic nucleus to structural component length scales, spanning in excess of 10 orders of magnitude, while time scales bridge more than 22 orders of magnitude ${ }^{16}$. Further, a wide range of variables controls the mix of nano/microstructural features formed and the corresponding degradation of physical and mechanical properties. The most important variables include the initial material microstructure, the thermal mechanical loads and irradiation history. Yet, radiation damage is the overarching concern for first wall and breeding blanket structures ${ }^{11-15}$.

At the smallest scales, radiation damage is continually initiated with the formation of energetic primary knock-on atoms through collisions between high-energy neutrons and lattice atoms. Concurrently, high concentrations of insoluble helium and hydrogen gas are generated in $(n, \alpha)$ and $(n, p)$ neutron capture reactions, which have threshold energies above several $\mathrm{MeV}$, hence are not normally produced in high quantities in fission neutron irradiations ${ }^{11-15}$. The primary knock-on atoms, as well as recoiling transmutant nuclei quickly lose kinetic energy through a chain of atomic collision displacements, generating a displacement cascade of vacancy and self-interstitial defects, in addition to electronic excitations. High-energy displacement cascades evolve over very short times, 100 picoseconds or less, and small volumes, with characteristic length scales of $50 \mathrm{~nm}$ or less, and are directly amenable to molecular dynamics (MD) simulations ${ }^{16-20}$. The physics of 
primary damage production in high-energy displacement cascades has been extensively studied with MD simulations and described in a number of excellent review articles ${ }^{18-20}$. The key conclusions from cascade studies are that i) intra-cascade recombination of vacancies and self-interstitial atoms (SIAs) results in $\sim 30 \%$ of the defect production expected from simple primary displacement theory, ii) many-body collision effects produce a spatial correlation (separation) of the vacancy and SIA defects, iii) substantial clustering of the SIAs and to a lesser extent, the vacancies occurs within the cascade volume, and iv) high-energy displacement cascades tend to break up into lobes, or subcascades which may also enhance recombination ${ }^{19,20}$.

Nevertheless, it is the diffusional transport and evolution of the defects produced in displacement cascades, in addition to solutes and transmutant impurities, that ultimately dictates radiation damage accumulation and changes in materials microstructure at nanometer/micrometer length scales. The evolution of local chemistry and structure at these scales is responsible for changes in physical and mechanical properties ${ }^{16,21-24}$. Spatial and temporal correlations associated with the displacement cascades continue to play an important role over much larger scales, as do processes including defect recombination, clustering, migration and gas and solute diffusion and trapping. Over such length and time scales, it is the time and temperature kinetics of diffusive and reactive processes, both within (cascade aging) and outside (long range migration) that govern micro/nanostructural evolution, albeit strongly influenced by the underlying sink structure of the microstructure and the continual production of new radiation damage.

While many of the controlling radiation damage processes and kinetics are known, quantitative details regarding the interactions amongst evolving species and indeed, even 
the transport, trapping/de-trapping and annihilation mechanisms of small defect-impurity clusters remain to be established. Fortunately, recent innovations in computational modeling, coupled with increasingly powerful high-performance computing and improved experimental tools, provide a basis to develop validated multiscale models of fusion materials performance. However, it is important to note that the complexity of modern engineering materials and multiple degradation processes occurring in the severe fusion environment makes this a tremendous long-term challenge, certainly on par with simulating a burning fusion plasma ${ }^{24}$. Furthermore, the challenge is made more difficult by the lack of available materials irradiation testing environments that can provide both representative displacement damage rates and representative rates of producing transmutations, most notably $\mathrm{He}$ and $\mathrm{H}$. This lack of an intense neutron source for materials testing emphasizes the need for a coordinated scientific effort combining experiment, modeling and theory to develop a fundamental understanding of radiation effects $^{14}$. This approach is currently being followed within the U.S. Fusion Materials Program.

The next subsection briefly describes the factors that involve structural materials selection criteria, the observed property changes in irradiated materials, along with an illustration of the material properties that define the design, or operating, window for fusion materials. The remainder of Section II describes the current status of reducedactivation materials for fusion and the unique requirements for an intense neutron source to test and ultimately qualify structural materials for the fusion energy environment, followed by a brief summary. 


\section{II.B. Fusion materials selection and design window}

The selection of structural materials for components in either nuclear fission or future fusion applications involves a compromise between strength and ductility, as described by Zinkle ${ }^{14}$. High strength materials generally have low ductility, and vice versa.

Furthermore, it is desirable that structural materials have the ability for significant plastic deformation prior to failure, including the ability to work harden, or become stronger when plastically deformed at stress levels above the yield stress up to elongations above several percent. Such work hardening ability provides robustness to component performance in the event of unanticipated service stresses, such as could be experienced in a plasma disruption event ${ }^{14}$. Very high strength materials generally provide little work hardening when plastically deformed, and usually experience less than a few percent of elongation before undergoing failure in uniaxial tensile tests. Of even greater concern, especially for body centered cubic metal alloys like ferritic or martensitic steels, is the tendency to exhibit brittle failure at low temperatures.

Under irradiation, there are several major degradation phenomena that can impact structural materials performance ${ }^{14}$. At low temperatures, defined as below about $35 \%$ of the melting temperature, radiation hardening and embrittlement is a primary concern for radiation doses above about 0.1 displacement per atom (dpa). In intermediate temperature regimes from about 30 to $60 \%$ of the melting temperature, instabilities in the microstructure of the material due to phase instabilities driven by radiation induced segregation and radiation enhanced diffusion and precipitation along with dimensional instabilities driven by volumetric swelling are the key concerns. These intermediate 
temperature phase and dimensional instabilities typically occur beginning with radiation exposures on the order of $10 \mathrm{dpa}$. At higher temperatures, defined as greater than about $40 \%$ of the melting temperature, thermal and irradiation creep, which involves the permanent plastic deformation of the material at stress levels below the yield stress, can cause significant strains in the material ultimately leading to rupture. Finally, at higher temperatures above about $60 \%$ of the melting temperature and high levels of transmutant helium production above about 100 atomic parts per million, helium embrittlement of grain boundaries can cause fast intergranular fracture, even at low stresses. The relatively high He production rates anticipated in fusion reactors can also alter many of the irradiation-induced microstructural evolution processes that cause these property degradations.

Figure 1 provides a schematic illustration of the materials design window for the fusion energy environment as a function of temperature. At low temperatures, materials lifetimes are limited by irradiation-hardening and fast-fracture, or so-called irradiation embrittlement. Dimensional instability or swelling, in addition to phase instabilities and microstructural evolution, limits performance at intermediate temperature. The high temperature performance is limited by thermal creep, and in some circumstances by irradiation creep that can limit performance at even lower temperature, in addition to schematic illustration is based on our present knowledge which is limited to relatively low levels of transmutant He production around 1000 parts per million. It is quite possible that higher He levels up to the design targets of 2000 parts per million may significantly reduce, or even close, the available materials design window. 


\section{II.C. Current reduced activation fusion materials}

Fusion materials research in the 1980's was focused on the evaluation of the microstructural stability of austenitic stainless steels at fusion relevant helium production and dpa production rates, and led to the selection of these steels for the first wall structures in ITER ${ }^{14,25}$. However, austenitic stainless steels exhibit relatively high levels of long-lived radioactivity as a result of high Ni concentrations. Furthermore, this class of steels has lower thermomechanical properties when compared to ferritic/martensitic steels and thus, austenitic stainless steels are no longer considered a candidate material for future fusion energy demonstration reactors.

Based on consideration of long-term radioactivity, short-term radionuclide safety and considerations of practical development of structural materials, three classes of high performance materials have emerged for fusion applications ${ }^{14,26}$. Namely, ferritic/martensitic steels containing $8-9 \% \mathrm{Cr}, 1-2 \% \mathrm{~W}, \mathrm{~V}$ and Ta; vanadium alloys containing $4-10 \% \mathrm{Cr}$ and $\mathrm{Ti}$; and silicon carbide based ceramic composites ${ }^{12-14}$. Interestingly, none of these materials existed in their current form 15 years ago. These low activation materials exhibit excellent thermal and mechanical properties and are also under consideration for application in a range of advanced fission-energy reactor concepts.

Of these alloys, the ferritic/martensitic steels are the most advanced and are believed to provide acceptable properties and performance within a fusion energy environment up to about 30 dpa and 300 appm (atomic parts per million) $\mathrm{He}^{27}$. However, these steels are likely limited to an upper operating temperature of 500 to $550^{\circ} \mathrm{C}$. Current and future 
efforts involve the development of advanced, nanostructured ferritic alloys which contain an ultra-high number density of nanoscale Y-Ti-O precipitate clusters in a ferritic Fe-12$15 \% \mathrm{Cr}$ alloy with promising corrosion resistance, creep strength and potential for radiation resistance ${ }^{8}$.

\section{II.D. Neutron source requirements}

Fusion power systems will require structural materials with lifetimes approaching 200 dpa and 2000 appm He in order to be economically viable. As previously mentioned, recent fusion materials research and development efforts have produced reducedactivation ferritic/martensitic structural materials with good radiation resistance to doses of about $30 \mathrm{dpa}$, but their performance in a high-dose fusion-relevant environment with accompanying high $\mathrm{He}$ and $\mathrm{H}$ generation from nuclear transmutations is unknown ${ }^{27}$. Because high levels of insoluble He can substantially impact microstructural evolution under irradiation, and correspondingly the materials bulk properties and performance, it is essential to carefully quantify the effect of $\mathrm{He}$ and displacement damage in order to develop a safe and reliable fusion power system. Therefore, a fusion-like neutron source is needed to generate a materials irradiation database for design, construction, licensing, and safe operation of next-step fusion nuclear devices and a fusion power system.

Several options exist for creating fusion-relevant neutron irradiation conditions, including the proposed International Fusion Materials Irradiation Facility ${ }^{28}$, the Materials Test Station ${ }^{29}$, and the Dynamic Trap Neutron Source ${ }^{30}$. Another possibility is to include 
provision for materials irradiation capability as part of a new large-scale nuclear facility such as the proposed Fusion Nuclear Science Facility ${ }^{27}$, but it should be emphasized that bulk material property data from a dedicated neutron source will likely be needed to enable the design, construction and licensing of such a facility.

In order to explore the simultaneous effects of displacement damage and $\mathrm{He}$ production on a wide range of materials various high-level international assessments have concluded that a suitable neutron source must reproduce the key attributes of the fusion spectrum, particularly in terms of the He-to-dpa ratio ${ }^{27-28}$. In addition, the neutron source must have flux and fluence capabilities that are sufficient to allow accelerated testing to end-of-lifetime doses in a reasonable time frame.

Thus, the basic requirements for an appropriate fusion materials irradiation facility are provided in Table I and include: $\geq 0.5$ liter volume with $\geq 2 \mathrm{MW} / \mathrm{m}^{2}$ equivalent $14 \mathrm{MeV}$ neutron flux to enable accelerated testing up to at least $10 \mathrm{MWy} / \mathrm{m}^{2}$ (with larger volumes at lower neutron fluences for testing larger components), availability $\geq 70 \%$, and flux gradients $\leq 20 \% / \mathrm{cm}$.

\section{II.E. Materials summary}

The development of advanced structural materials is a key feasibility issue for the future of fusion power. The effects of irradiation on materials property and performance degradation include irradiation hardening and embrittlement at low temperatures and creep and helium embrittlement at high temperatures. However, the full effects of high levels of helium on reducing, or even closing, the fusion materials design window have 
not been fully established. The current U.S. fusion materials program is based on a scientific approach that combines advanced modeling and simulation with theory and experimentation, and has led to high-performance, reduced-activation materials with a design window on the order of $30 \mathrm{dpa}$ and 300 appm He for temperatures less than about $550^{\circ} \mathrm{C}$. However, fusion materials development is substantially hindered by a lack of a representative fusion neutron materials testing environment. The key requirements for an intense fusion neutron source that is capable of providing an energy-dependent neutron flux effectively equivalent to the first wall of a deuterium-tritium fusion power reactor include:

- Greater than 0.5 liter volume with greater than $2 \mathrm{MW} / \mathrm{m} 2$ equivalent $14 \mathrm{MeV}$ neutron flux;

- Greater than $70 \%$ availability to enable testing to exposures greater than $10 \mathrm{MW}$ $\mathrm{y} / \mathrm{m} 2$; and

- Flux gradients less than or equal to $20 \% / \mathrm{cm}$.

\section{MATERIAL AND BLANKET SUBCOMPONENT TESTS}

Breeding blanket systems have many possible designs, materials, and configurations. The primary blanket options currently considered worldwide as candidates for DEMO can be classified into: a) solid breeders, b) separately cooled liquid metal breeders, and c) dual-cooled liquid metal breeders, as presented in Table II. Material and blanket technology development up to DEMO requires qualification and testing to resolve the many known issues as well as those presently unknown. The term "test" is used here in a 
generic sense to describe a process of obtaining information through physical experiments and measurements. The types of tests are distinguished by the relevant test article sizes and by the level of integration of the test. For each breeding blanket material system, there is a set of tests ranging from property measurements to component verification. The test categories adopted in previous studies ${ }^{31,32}$ and illustrated in Figure 2 are: basic, single effect, multiple effect/multiple interaction, partially integrated, integrated, and component tests. Specimens, elements, and submodules can be used to address basic, single effect, and multiple effect/multiple interaction issues. A very important conclusion from previous studies is that integrated and component tests can be performed only in fusion devices. However, it is essential to have in hand an adequate understanding of individual phenomena so that integrated testing will provide data, which can be interpreted and compared with design codes. Thus, a test article simulating a portion of the blanket to examine a particular group of multiple effects for testing in the fusion environment would provide data for model improvement and simulation benchmarking. It also helps screen material combinations and design concepts.

Nuclear reactions in fusion blankets lead to several important phenomena that impact material and blanket performance. Neutrons and secondary gamma rays are absorbed, leading to the generation of volumetric nuclear heating that varies in magnitude and profile, depending on the blanket design. The fusion energy is not deposited uniformly in the blanket, but will have strong spatial variations, which fall off strongly with distance from the first wall. Since neutrons are the only practical source of nuclear heating in a large volume and they are also necessary to simulate radiation effects, a test facility that generates neutrons resembling those from fusion nuclear reactions with an adequate 
neutron wall load, surface area, and test volume is valuable for material and blanket subcomponent tests. The nuclear environment from a GDT neutron source (DTNS) device is such an example, and is suitable for performing single and multiple effect tests that are needed to establish the proof-of-principle for certain designs. It can potentially provide an engineering database for specific issues or elements of the designs using submodule test vehicles. These issues include (i) tritium transport and permeation, (ii) thermomechanical responses of blanket elements, (iii) material compatibility, and (iv) weld behavior and failure modes. Examples include tests of a unit cell of solid breeder blankets used to investigate tritium release behavior as well as some aspects of breeder/structure interactions. In the following section, example test vehicles are described to provide guidance on how the DTNS can be utilized as a fusion blanket/material test facility to cover blanket submodule multiple-interaction tests, in addition to the material tests as already discussed in Section II and Ref 3.

The available test volume inside the irradiation rig of a DTNS appears adequate to conduct tritium recovery and permeation quantification experiments up to the expected lifetime for candidate breeder and structural materials. The release of tritium from ceramic breeders, the solubility of tritium in liquid breeders, and the permeation of tritium through reduced activation ferritic steel (RAFS) structures are all strongly dependent on the temperature of the materials, chemical compositions, and surface conditions. Using the tests information together with predictions and measurements of tritium production, a picture of tritium transport and permeation can be constructed and compared against coupled system simulations. Post irradiation examination (PIE) of breeder and structural materials following exposure can help quantify tritium inventories 
in various materials and components following long operation. The test may also be conducted in the region where the magnetic field is expected to alter the liquid metal velocity profile to study its effect on tritium permeation.

The temperatures and temperature gradients of the blanket materials strongly influence the blanket's behavior. The stress generated from the temperature gradient as well as the thermal expansion mismatch between joints or between the breeder and structural clad materials makes the study and understanding of thermo-mechanical effects on blanket performance particularly challenging. There is a need to verify the ceramic breeder 'pebble beds' mechanical stability on withstanding the combined temperature gradients and mechanical constraints on a larger scale as in the HEXCALIBER ${ }^{33}$ mockups. As shown in Fig. 3, the mock-up consists of a first wall and welded cells made in DEMO structural ferritic-martensitic steel. The breeder cell designed to reproduce the reference pebble temperature magnitudes, consists of two lithium orthosilicate (OSi) pebble beds and two Be pebble beds, each of them heated by two flat electrical heaters. There appears to be space available in the DTNS facility to accommodate the mock-up dimensions of $540 \mathrm{~mm}$ in width, $250 \mathrm{~mm}$ in depth, and $254 \mathrm{~mm}$ in height. In addition, the DTNS fusion-testing environment directly provides a fusion reactor relevant thermal loading condition, without the use of electrical heaters, as in the mock-up to simulate nuclear heating. Electrical heaters disadvantageously disturb blanket pebble bed configurations while giving non-prototypical temperature profiles.

The EXOTIC ${ }^{34}$ irradiation experiments for ceramic breeder and the LIBRETTO $^{35}$ experiments for Pb-17Li alloys in the High Flux Reactor (HFR) at Petten were designed to investigate tritium release forms, properties, and residence time. Similar tests can be 
performed in DTNS not only for reproduction of fission reactor experiments, but more importantly for the extrapolation of these results to fusion conditions. The maximum allowable operating temperature at high fluence/high constraint for candidate ceramic breeder materials is yet to be defined, while tests can also be designed using DTNS for exploring mechanical stability of the fabricated ceramic pebbles at different levels (up to DEMO levels) of Li burn-up as well as its performance at high temperatures under a prototypical ratio of $\mathrm{dpa} /{ }^{6} \mathrm{Li}$ burn-up as attempted in the $\mathrm{HICU}^{36}$ (high fluence irradiation of ceramic breeder pebble beds) irradiation experiments. The drums used in HICU to hold the pebbles are shown in Figure 4.

Radiation damage affects structural materials, breeding and neutron multiplying media, permeation barriers, and insulator materials such as flow-channel inserts (FCI) through degradation processes that include hardening, embrittlement, phase instabilities, segregation, precipitation, irradiation creep, volumetric swelling, helium embrittlement, and radiation-induced changes in thermal and electrical properties. Similar to the IFMIF, structural material specimen irradiation tests can be conducted in the DTNS facility ${ }^{3}$. At the same time structural elements such as tubes, welds, etc. should be tested in parallel to help interpret the results. Specifically, the mechanical properties of materials (yield strength, ductility, fracture toughness, creep strength, fatigue resistance, etc.) are strongly influenced by operating temperature and temperature variations, the microstructure produced during initial fabrication and subsequent heat treatments, adsorption of impurities from coolants or as a result of transmutation due to nuclear reactions, effects of radiation damage, etc. All these factors should be considered simultaneously to better understand irradiation effect on lifetime performance or blanket material system failure 
modes. In this regard, very little work has been done to date to identify failure modes associated with blanket material systems. Some of the possible structural element failure modes that should be of concern are: (1) cracking and de-lamination around a discontinuity/weld, (2) environmentally assisted cracking, and (3) structure swelling and creep leading to excessive deformation or failure. Deformations (strains) can be measured under different fluid, mechanical, and thermal operating conditions; providing important information for validating structural mechanics simulations for improved future blanket designs. An example of this can be the joint and/or weld specimen, of which the performance degradation/failure may be affected by the environmental conditions in addition to radiation damage. A submodule as shown in Figure 5 involving weld and pipe joint samples under prototypical thermomechanical constraints and fluid operating conditions can be tested in DTNS facility to screen joining/welding processes.

Corrosion mass transport and redeposition are expected to be a blanket safety and maintenance concern due to the movement of radioactive or hazardous transmutation corrosion products into the support systems outside of the fusion blanket. Measurement of chemistry and radioactivity inside and outside of the fusion environment gives good qualitative information concerning mass transport in blanket systems. $\mathrm{A} \mathrm{Pb}-17 \mathrm{Li}$ corrosion test loop using the RAFS test pipes with SiC FCI inserts can be constructed in the DTNS irradiation zone with an ancillary loop located outside the irradiation area to shed more light on $\mathrm{Pb}-17 \mathrm{Li}$ mass transport behavior through identification of points of preferential corrosion, erosion or redeposition sites.

Satisfactory testing of the material and blanket in any fusion environment imposes important requirements on the design of the testing facility in at least two areas: 1) major 
parameters, and 2) engineering design. The major parameters of concern are those that have major impact on both the usefulness of the tests such as the machine's plasma duty cycle, burn duration, availability, and the cost of the device. The requirements on the engineering design include providing capabilities for fast insertion and removal of test modules, access to many coolants, tritium processing and instrumentation lines, and suitably located space and facilities for ancillary equipment to support the test program. The major auxiliary systems for conducting material and blanket submodule tests in DTNS include coolant systems, the instrumentation and control systems for temperature control, active type experimental systems, and test disassembly and reconstitution systems. 


\section{IV.PREVIOUS MIRROR NEUTRON SOURCES}

\section{IV.A. TASKA, TDF, and TASKA-M}

Responding to the need for a D-T fusion neutron source, researchers designed three conceptual fusion neutron test facilities based on the magnetic mirror configuration in the early 1980s: TASKA ${ }^{38}$, TDF $^{39}$, and TASKA-M ${ }^{40}$. Motivated by the accessibility and maintainability of cylindrical geometry, these designs share with the GDT-based DTNS a relatively simple central cell. The TASKA-M design, like DTNS, included the injection of neutral beams into the central cell to create a "sloshing ion" distribution that gives density peaks near the materials test modules. In TASKA and TDF, the end-cell designs were minimum-B end cells containing thermal barriers: regions of low electrostatic potential that reduce electron flow and thermal conductivity between the central cell and end cells. Thermal barriers allow better plasma performance, but they require more complicated input power systems and their physics basis is established in only a small range of parameters ${ }^{41}$. For TASKA-M, in order to assess the capabilities of a more conservative design, minimum-B end cells were included to provide magnetohydrodynamic (MHD) stability; thermal barriers and an end-plug potential to contain ions were absent. Fig. 6 illustrates key features of TASKA, TASKA-M, and TDF.

Selected parameters for TASKA, TDF, and TASKA-M are given in Table III. The conceptual design team for TASKA was the University of Wisconsin (UW), Kernforschungszentrum Karlsruhe (KfK), Interatom, Grumman Aerospace, Babcock and 
Wilcox (B\&W), General Atomic (GA), Hanford Engineering Development Laboratory (HEDL), and Lawrence Livermore National Laboratory (LLNL). The TDF team was LLNL, the Oak Ridge National Laboratory Fusion Engineering Design Center (ORNL FEDC), TRW, General Dynamics (GD), UW, Bechtel, Science Applications Incorporated (SAIC), Los Alamos National Laboratory (LANL), University of California-Los Angeles (UCLA), and Massachusetts Institute of Technology (MIT). The TASKA-M team was UW, KfK, LLNL, HEDL, University of Karlsruhe, and University of Krakow. In Table 1 the acronyms are $\mathrm{NB}$ - neutral beam, ICRF - ion cyclotron range of frequencies, and ECRF - electron cyclotron range of frequencies. The tandem mirror concept ${ }^{42,43}$ contains a potential peak in the end cells to reduce central cell ion losses. The thermal barrier concept $^{44}$ invokes a potential dip between the central cell and end cell to reduce electron thermal contact, allowing a warmer end cell electron temperature and resulting in a higher ion-confining potential for less input power.

The axial profiles of magnetic field and electrostatic potential for TASKA, TDF, and TASKA-M appear in Figure 7 and illustrate some key design choices. The earliest design, TASKA, chose to separate the electrostatic thermal barrier from the ion plugging electrostatic potential in the end plug, which embodied the recently invented thermalbarrier tandem mirror concept as it was then envisioned. The TASKA neutral beams that pumped impurities and alpha-particle ash from the thermal barrier totally fueled and partially heated the central cell, and ICRF heating generated the remaining input power required for plasma power balance. The plug regions required a total of $15 \mathrm{MW}$ of ECRF power and 5.4 MW of neutral beam power injected at an energy of $250 \mathrm{keV}$. The TDF design significantly shortened the device's length by combining the thermal barrier and 
end plug into a single cell as in the TMX-U experiment ${ }^{41}$, which had recently also demonstrated the sloshing-ion concept ${ }^{45}$. This approach reduced the length and input power substantially compared to TASKA for nearly the same neutron wall loading. It also allowed the use of $51 \mathrm{MW}$ of $80 \mathrm{kV}$ neutral beam injection at an angle into the central cell to make most of the ions there be mirror-trapped. This reduced the requirements on the end-plug potential to only $17 \mathrm{kV}$ from $125 \mathrm{kV}$. For TASKA-M, the design aimed for small size by using sufficient power in neutral beams injected at an angle into the central cell to create a sloshing-ion population and by placing the main materials test modules near those peaks. A key TASKA-M decision was to create a relatively conservative design that did not invoke thermal barriers or ion end plugging and required minimum-B end cells only for MHD stabilization, leading to a short central cell.

\section{IV.B. Beam Plasma Neutron Source (BPNS)}

The Beam-Plasma Neutron Source (BPNS), shown in Fig. 8 produces a neutron flux similar in magnitude to that from the IFMIF over a volume exceeding that of FMIT $^{46}$ (an earlier U.S.A. version of IFMIF) by factors of $\sim 2^{47-49}$, as shown in Fig. 9. Like other fusion-based neutron sources, such as discussed in Section IV.A., it has additional advantages: it produces $14 \mathrm{MeV}$ DT-fusion neutrons with no higher energy neutrons, which IFMIF will generate; neutrons above $14 \mathrm{MeV}$ can produce activation that would not occur in a fusion power plant. The BPNS neutron energy distribution, unlike the 
IFMIF, is independent of axial or azimuthal position. Neutral-beam injection can maintain low impurity levels so that impurity radiation is not an issue $\mathrm{e}^{50}$.

The Beam-Plasma Neutron Source (BPNS) is based on the 2XIIB minimum-B neutralbeam sustained magnetic mirror that confined ITER-grade ions in $1976\left(\mathrm{n}_{\mathrm{e}} \sim 1-2 \times 10^{20} \mathrm{~m}^{-3}\right.$, $E_{i}=10 \mathrm{keV}$ ) with stable operation at beta near or exceeding unity; however, $T_{e}$ was only about $1 \%$ of the ion energy ${ }^{51}$. MHD stability was guaranteed by the good-curvature of the minimum-B magnetic field lines at high- $\beta$ ( $\beta=$ plasma pressure/ vacuum magnetic-fieldpressure). The electron temperature, $T_{e}$, was lowered by adding a dense, warm, unconfined plasma, This warm plasma can then stabilize modes driven by pressure anisotropy or an empty loss cone; when unstable, these modes oscillate at ion-cyclotron range of frequencies, scattering ions into the loss cone more rapidly than the classical processes of electron drag cooling of hot ions coupled with ion-ion scattering that moves them into the loss cone.

Compared with the DTNS, the electron temperature was lower, $200 \mathrm{eV}$ rather than $700 \mathrm{eV}$. This is because the BPNS had a much denser warm flowing plasma that limited $T_{e}$ by thermal conduction to the end walls, whereas the DTNS has a lower density warm plasma and a larger magnetic field expansion to the ends that decouples $T_{e}$ from end-wall electron emission. The lower $\mathrm{T}_{\mathrm{e}}$ in the BPNS limited the fusion gain to $\mathrm{Q} \sim 0.01$, rather than the $\mathrm{Q} \sim 0.07$ predicted for the BPNS.

The neutral beams were injected nearly normal to the magnetic field in the BPNS, which had one advantage over the DTNS, the hot plasma density was higher in the smaller volume yielding a higher neutron flux, but with two negative consequences: approximately half of the circumference around the hot plasma was occupied by neutral 
beam injector or dump ducts rather than by samples to be irradiated, and the neutral beams were exposed to the peak neutron flux.

The base case for the BPNS used minimum-B coils around the hot plasma for MHD stability. The coil design limited the magnetic field strength, the access for neutral beams and test samples, and produced elliptical plasma cross-sections off the midplane that increased the average radius (hence lower neutron flux) at which samples could be placed. Alternate BPNS designs assumed axisymmetry, which was found to allow higher neutron flux for a given neutral beam power, but at that time, we did not know whether MHD stability could be provided at high beta, a issue that subsequent experiments on the GDT have removed by demonstrating axisymmetric stability at beta up to 0.6.

\section{The Dynamic Trap DT Neutron Source (DTNS)}

\section{V.A. Overview}

The DTNS nominal design is aimed to produce $2 \mathrm{MW} / \mathrm{m}^{2}$ of neutron flux ${ }^{1-3,52}$. Figure 10 shows that the output flux depends on electron temperature, because electron drag cools the deuterium and tritium ions. So to obtain the design neutron flux it is necessary to operate with an electron temperature of $\sim 600 \mathrm{eV}$. For reference, the GDT experiment achieves $200 \mathrm{eV}$ temperatures with 8 times less heating power.

The DTNS achieves MHD stability in an axisymmetric geometry, which requires only circular magnets coils. It provides an even larger neutron irradiation volume with several other advantages over either the BPNS or IFMIF: (1) Higher $\mathrm{T}_{\mathrm{e}}$ allows a larger irradiated volume with lower neutral beam power ${ }^{3}$. (2) The neutral beams inject near the 
midplane where neutron production is a factor of 10 lower than the peaks at either end, this extends the lifetime of the neutral beams (against activation and radiation damage) by $\times 10$ compared with a BPNS or a tokamak based volume neutron source. Another advantage of injecting away from where the neutron-flux peaks is that the space occupied by beam injection and beam dump ducts do not displace neutron irradiation test regions. (3) The two peak neutron flux regions at either end of the DTNS can be optimized for different purposes: for example, one end for material studies; the other end with a larger volume for component tests, such as tritium-breeding blanket modules, fusion-fission hybrid modules; or one end for long term irradiations, the other for shorter terms. 4) The axisymmetric design maintains a circular plasma cross section, which allows irradiation of samples closer to the axis in a higher neutron flux than with the elliptical cross section of minimum-B plasma. Finally, the scattered neutron energy spectrum can closely approach that of ITER or DEMO, as will be discussed ${ }^{3}$.

A schematic illustration of a DTNS is seen in Figure 11. Illustrated are magnets, (superconducting and copper coils), neutron shielding and neutral beam injection systems. Shown on the right is a $2.5 \mathrm{~m}$ zone for small samples (inserted axially) and on the left is a $1 \mathrm{~m}$ long zone for components (inserted radially). The $2.5 \mathrm{~m}$ zone provides a volume of 201 , over an annulus that is $0.025 \mathrm{~m}$ thick, approximately $59 \%$ of this volume is filled with samples in the present design. Because this layer is thin relative to its radius, the neutron flux is nearly constant across it; so all samples are irradiated at a similar rate, which is near the maximum $2 \mathrm{MW} / \mathrm{m}^{2}$. Note that the magnets are shielded from neutrons for longer life and reduced cooling power. The neutral beams inject near the midplane where neutron production is an order of magnitude lower than at either end at the 
irradiation test regions, reducing radiation damage to the injectors and associated cryopumps.

The DTNS mirror-to-mirror length is slightly longer than in the GDT. Compared to GDT, the DTNS has 10 times higher neutral beam injection power, as well as 4 times higher ion energy, electron temperature, plasma density, and magnetic field. Both systems have similar beta (60\%), ion gyro-radius, and neutral beam penetration depth. Thus the two systems are dimensionally similar. Fischer, Möslang, and Ivanov $^{3}$ have assessed the neutronic characteristics. In Fig. 12 we see that the first-wall neutron-spectra from DTNS is virtually identical with that of ITER (in contrast to IFMIF). This means that measurements of neutron damage from dpa or helium embrittlement can be applied to ITER or DEMO, without the uncertainties of correcting for the neutron energy spectrum, and that activation products will not include (false positive) isotopes with production thresholds exceeding $14 \mathrm{MeV}$. Maintaining the ITER-like neutron spectrum in the much smaller DTNS requires care in designing the neutron reflectors.

The radial and axial uniformity of DTNS is illustrated in Fig. 13 (calculated in Ref. 3 ). It is seen that the uniformity is better that the $20 \%$ per $\mathrm{cm}$ requirement for materials irradiation testing.

The design of a tubular test assembly capable of accommodating as many as 8,000 miniaturized specimens in a volume of 201 is illustrated in Fig 14(a-d). These are located outside of the DTNS vacuum wall, so that samples can be changed without an air-cycle, and mechanical and electrical stresses can be applied and measured more conveniently. Helium gas provides cooling without significant interaction with the neutrons, and 
without chemically reacting with samples, some of which will be at elevated temperatures.

\section{V.B. The technical readiness of key DTNS systems}

Based on previous mirror neutron source studies and the state of technology developed within the ITER program we conclude that the only missing element is steadystate neutral beam system. DTNS needs much lower energy beams than are being developed for ITER. The DTNS requires 65 to $80 \mathrm{keV}$ beams at a power level now common on tokamaks such as JET, DIII-D, TFTR, etc. These beam systems are presently limited to several second pulses, primarily by the beam line - not the source module. The needs of DTNS are similar to those of EAST, KSTAR, JT-60SA as well as potential US devices such as FNS or CTF. With this worldwide need and market opportunity, steady-state neutral beams are expected to be developed.

Two other systems, magnets and tritium systems, would also employ current technology but are worthy of mention: magnets, because they are rather high field $(\sim 12-$ 30 Tesla); tritium handling, because the gas throughput of the DTNS is substantial.

\section{V.C. Steady-state neutral beams}

The long-pulse ion source, developed by LBNL for TFTR and DIIID ${ }^{53}$, proved to be highly reliable, with availabilities exceeding $90 \%$ on DIIID ${ }^{54,55}$, and approaching $95 \%$ on TFTR $^{56}$. The version used on DIIID, operating at $80 \mathrm{keV}$ with $80 \mathrm{~A}$ of ion current, is close to the requirements for a DTNS which needs $65-80 \mathrm{keV} \mathrm{D}$ and T ions ${ }^{3}$. 
Steady-state operation will require further development of the beam lines components used on TFTR and DIIID. The most complex component, the ion accelerator is already cooled for steady-state operation; successful operation of the water-filled molybdenum tube electrodes has been demonstrated for more than 10 thermal time constants in the 1-5 sec operation achieved in present day beam lines. A possible cooling technology for larger components, hypervapotron arrays ${ }^{57}$, has been used extensively and successfully on JET. This is a candidate for cooling ion-beam dumps, calorimeters, apertures, and beam dumps on the far side of the plasma. Additional cooling is needed on the back-side of the ion source (if the accelerator were to operate above $80 \mathrm{keV}^{53}$ ) to handle heating from backwards-accelerated electrons, the mask defining the plasma source grid aperture, and possibly other areas, such as neutralizer ducts ${ }^{56}$.

Additional engineering to achieve steady-state operation is needed in two areas: (1) the present hot-filament cathodes are expected to last a minimum of 12 days (lifetimes have not been established, and may be significantly greater than this), based on present pulsed performance, We ultimately need lifetimes at least an order of magnitude greater than this in the DTNS. (2) Cryopumping can handle the steady-state gas loads, but additional pumping area must be supplied so that a portion of the pumps can be off-line for regeneration, and the maximum time between regenerations needs to be determined to ensure that the hydrogen isotope accumulation remains well below the explosive limit in all parts of the DTNS in the worst case of a significant air-leak.

A neutral beam manufacturing capability needs to be established for the DTNS, or for any tokamak-based neutron sources. The RCA Power Tube Division built the original Long-pulse ion sources for DIIID and TFTR during 1984-88. That capability no longer 
exists. GA has successfully built the most critical replacement accelerator electrodes, which have performed well in subsequent tests ${ }^{58}$. Manufacture outside of the U.S.A. may also be possible.

Beam focusing in the narrow plane could enhance DTNS operation by allowing plasma diameters smaller than $\sim 25 \mathrm{~cm}^{55}$, which would reduce end losses and enhance the fusion gain-factor, Q. Beam focusing in both planes was demonstrated in TMX-U, where curved electrode wires were assembled on a cylindrically curved surface, producing focusing to the centers of curvature ${ }^{59}$. Narrow-plane focusing could be incorporated in the long-pulse sources by bending the molybdenum electrode tubes into a cylindrical shape with the center of curvature at the beam focus position (possibly done in a curved restraint during heat-treatment and stress relieving). Focusing in the longer plane was accomplished for the DIII-D $80 \mathrm{keV}$ neutral beams by building each accelerator electrode with 5 flat cards, the outer cards inclined inwards to focus outer beamlets onto the same area as inner beamlets ${ }^{53}$. The effects of focusing would need to be revaluated at each beam dump location, to ensure that peak powers do not exceed cooling capabilities.

Beam focusing on the entrance aperture to a torus could also benefit tokamak neutron sources by reducing the size of the aperture, hence the number of neutrons entering the neutral beam line.

These issues can be handled with a four-phase DTNS program that may be preceded by further experiments on the GDT or an upgraded facility:

a. Beam-line assembled first - begin neutral beam commissioning, testing, and further development as required. All elements needed for steady-state operation can be tested, and developed further as required, including beam dumps and duct 
cooling on the far side of the plasma which will handle lower power densities when plasma is present.

b. Hydrogen-operation of DTNS - beginning with long pulse and increasing to steady state. No neutron shielding is required. This will demonstrate neutral beam injectors and mirror physics.

c. Deuterium-operation - requires neutron shielding but no tritium-handling system. Compare the neutron flux, and the increase in $\mathrm{T}_{\mathrm{e}}$, and beta with expectations, for assurance of DT performance.

d. Deuterium-Tritium operation - can begin at low tritium concentration and increase to $\sim 50 \%$ as systems are commissioned. Compare parameters with expectations, begin materials and component testing program.

\section{V.D. Magnets}

The Efremov Institute in St. Petersburg, Russia has designed a number of DTNS magnets $^{4,60-63}$. Magnet design requirements included providing access for neutral beam injectors and beam dumps at 30 to $40^{\circ}$ from the axis, aimed at the midplane of the DTNS, and that these be adequately shielded from neutrons ${ }^{62,63}$, which peak at the ion turning points. Magnet designs have included all superconducting coils as well as hybrid magnets with high field copper insert coils to reach 25-26 Tesla (for higher fields and mirror ratios). Shown in Fig. 11 is one example of such a hybrid magnet system. All superconducting mirror coils were studied after finding that half of the power consumption (30 MW) was required to reach $26 \mathrm{~T}$ with a design of hybrid mirror coils; 
superconducting coils achieved similar mirror fields of $24.5 \mathrm{~T}$ in a $60 \mathrm{~cm}$ bore by using $\mathrm{Nb}_{3} \mathrm{Sn}$ conductor and cooling to $1.8 \mathrm{~K}^{64,65}$. Other groups have generated solenoidal fields of $14 \mathrm{~T}$ in a $60 \mathrm{~cm}$ bore with superconducting coils; by adding resistive inserts this system reached up to $45 \mathrm{~T}^{66}$. The ITER Central Solenoid Model Coil has been tested to $13 \mathrm{~T}$ peak field, in a $1.6 \mathrm{~m}$ diameter bore ${ }^{67}$. This work, as well as that carried out earlier in the US convinces us that magnets required for DTNS are within engineering capability.

An example of a neutron-shielded magnet design from Effremov institute [Ref 61] is shown in Fig. 15. Neutrons are generated by the hot-ion plasma (7) on axis at the left half of the figure. Samples to be irradiated (8) surround this plasma, with shielding between the samples and the solenoidal superconducting magnets (4 and 5) located at larger radii. The neutrons at the magnet positions are computed with the code MCNP-A ${ }^{68}$. The mirror coils are to the right, and include an outer superconducting magnet (3) that is carefully shielded from neutrons, with resistive inserts (1 and 2) that have less, or no, shielding.

\section{V.E. Tritium Processing}

While the consumption of tritium in DTNS is modest ( $\sim 150$ grams per year), the flow rate of tritium and deuterium recirculating in the system is substantial. There are three isolated regions of gas flow: plasma chamber, neutral beam tanks, and the end tanks; each of these operates on a mixture of deuterium and tritium). Since mixtures of deuterium and tritium can be tolerated in neutral beam fueling of the hot ions and in gas (or pellet) fueling of the warm plasma, gas processing can be simplified by not separating tritium 
from deuterium. To maintain the desired fractions of each component, it is sufficient to use cryopanels at different temperatures ${ }^{69}$. It will be possible in initial DT operation to gradually increase the tritium concentration from near zero to $\sim 50 \%$, as the commissioning of the tritium/gas system, neutron production, and neutron shielding progresses. Gases other than deuterium and tritium must be maintained below a level to be determined; this may be the major issue for the gas-handling system.

\section{RECOMMENDED FUTURE ASSESSMENT AND ANALYSIS}

A number of aspects of the DTNS concept warrant further analysis in order to better optimize its characteristics

1. Obtain a better understanding of the scaling of parameters from the GDT experiments to the DTNS parameters, including testing details of the rotational stabilization mechanism.

2. Seek ways to reduce the throughput of warm plasma flow in order to raise the electron temperature and to reduce the tritium inventory. Maintaining MHD stability and micro-stability are likely to limit how far the warm-plasma flow can be reduced. 


\section{ACKNOWLEGEMENTS}

This paper is based on a workshop that was held at LBNL, Berkeley, CA on March 12, 2009 to "Assess the mission and technology of a Gas Dynamic Trap Neutron Source for

fusion material and component testing and qualification." This work performed under the auspices of the U.S. Department of Energy, Oak Ridge Associated Universities, and the Lawrence Livermore National Laboratory under Contract DE-AC52-07NA27344. 


\section{REFERENCES}

1. A. A. IVANOV, E. P. KRUGLYAKOV, Yu. A. TSIDULKO, V. G. KRASNOPEROV, and V. V. KORSHAKOV, "Conceptual Design Studies of GDTBased Neutron Source," Symposium on Fusion Engineering, Champaign, IL, 30 Sept. - 5 Oct. 1995, IEEE 1996, Vol. 1, p. 66.

2. A. A. IVANOV, E. P. KRUGLYAKOV, and Y.A. TSIDULKO, "A first step in the development of a powerful $14 \mathrm{MeV}$ neutron source," J. Nucl. Mat. 307-311, 1701 (2002).

3. U. FISCHER, A. MÖSLANG, and A.A. IVANOV, "Assessment of the gas dynamic trap mirror facility as intense neutron source for fusion material test irradiations," Fusion Engineering and Design 48, 307 (2000).

4. V. V. KORSHAKOV, V. G. KRASNOPEROV, A. A. IVANOV, Yu. A. TSIDULKO, and G. I. BUDKER, "Design of the magnet system for neutron yield zone of the plasma neutron source based on the gas dynamic trap. Fusion Technology 35, 195 (1999).

5. P.A. BAGRYANSKY, A.D. BEKLEMISHEV, M.S. CHASCHIN, and E.I. SOLDATKINA. "Radial electric field and radial currents in the Gas-Dynamic Trap." Fus. Sci. Techn. 51, 337 (2007).

6. P.A. BAGRYANSKY, A.D. BEKLEMISHEV, and E.I. SOLDATKINA. "Influence of radial electric field on high-beta plasma confinement in the Gas-Dynamic Trap." Fus. Sci. Techn. 51, 340 (2007). 
7. A.D. BEKLEMISHEV. "Shear-flow effects in open traps." In: "Theory of fusion plasmas," AIP Conference Proceedings 1069, 3 (2008).

8. G.R. ODETTE, M.J. ALINGER and B.D. WIRTH, Annual Review of Materials Research 38, 471 (2008).

9. G.S. WAS, "Materials degradation in fission reactors: Lessons learned of relevance to fusion reactor systems," J. Nucl. Mat., 367-370, 11 (2007).

10. http://www.engineeringchallenges.org/cms/8996/9221.aspx

11. E. E. BLOOM, J. Nucl. Mat., 258-263, 7 (1998).

12. E. E. BLOOM, N. GHONIEM, R. JONE, R. KURTZ, G. R. ODETTE, A. ROWECLIFFE, D. SMITH and F. W. WIFFEN, “Advanced Materials Program”, appendix D of the VLT roadmap, 1999, available at http://vlt.ucsd.edu/.

13. S.J. ZINKLE and N.M. GHONIEM, Fusion Engineering \& Design 51-52, 55 (2000).

14. S.J. ZINKLE, "Fusion materials science: Overview of challenges and recent progress," Physics of Plasmas 12, 058101 (2005).

15. T. MUROGA, M. GASPAROTTO, and S.J. ZINKLE, Fusion Engineering \& Design 61-62, 13 (2002).

16. G. R. ODETTE, B. D. WIRTH, D. J. BACON and N. M. GHONEIM, "MultiscaleMultiphysics Modeling of Radiation-Damaged Materials: Embrittlement of Pressure Vessel Steels", MRS Bulletin 26, 176 (2001).

17. R. E. STOLLER, G. R. ODETTE and H. L. HEINISCH, "A Whitepaper Proposing an Integrated Program of Theoretical, Experimental and Database Research for the 
Development of Advanced Fusion Materials", prepared for the Office of Fusion Energy Sciences, U.S. Department of Energy (1999).

18. J. B. GIBSON, A. N. GOLAND, M. MILGRAM, and G. H. VINEYARD, Phys. Rev. 120, $1229(1960)$.

19. A. F. CALDER and D. J. BACON, J. Nuc. Mat. 207, 25 (1993).

20. W.J. PHYTHIAN, R.E. STOLLER, A.J.E. FOREMAN, A.F. CALDER, and D.J. BACON, J. Nuc. Mat. 223, 245 (1995).

21. G. R. ODETTE, J. Nuc. Mat. 85 \& 86, 533 (1979).

22. L. K. MANSUR and E. E. BLOOM, Journal of Metals, 34, 23 (1982).

23. B. N. SINGH and A. J. E. FOREMAN, J. Nuc. Mat., 122 \& 123, 537 (1984).

24. B.D. WIRTH, G.R. ODETTE, J. MARIAN, L. VENTELON, J.A. YOUNG and L.A. ZEPEDA-RUIZ, Journal of Nuclear Materials 329-333, 103 (2004).

25. M.L. GROSSBECK, K. EHRLICH and C. WASSILEW, J. Nuc. Mat. 174, 264 (1990).

26. D.R. HARRIES, G.J. BUTTERWORTH, A. HISHINUMA, and F.W. WIFFEN, $J$. Nuc. Mat. 191-194, 92 (1992).

27. FESAC Greenwald report on "Priorities, Gaps and Opportunities: Towards a LongRange Strategic Plan for Magnetic Fusion Energy", available at: http://www.sc.doe.gov/ofes/fesac.shtml.

28. IFMIF Comprehensive Design Report, by the IFMIF International Team, Jan 2004; R. A. JAMESON, R. FERDINAND, H. KLEIN, J. RATHKE, J. SREDNIAWSKI, 
M. SUGIMOTO, "IFMIF accelerator facility," J. Nuc. Materials 329, 193 (2004); H. NAKAMURA, R. RICCARKI, N. LOGINOV, K. ARA, L. BURGAZZI, et al., "Present status of the liquid lithium target facility in the IFMIF," ibid, p. 202; V. HEINZEL, P. BEM, E. ESPOSITO, S. GORDEEV, U. FISCHER, A. MOESLANG, et al., "Overview on the IFMIF test cell development," ibid p. 223.

29. E.J. PITCHER, J. Nuc. Mat. 377, 17 (2008).

30. A.A. IVANOV, E.P. KRUGLYAKOV, and Y.A. TSIDULKO, J. Nucl. Mat. 307311, 1701 (2002).

31. M. ABDOU et. al., "Results of an International Study on a High-Volume PlasmaBased Neutron Source for Fusion Blanket Development," Fusion Technology 29, 157 (1996).

32. M. ABDOU, et. al., "Technical Issues and Requirements of Experiments and Facilities for Fusion Nuclear Technology" Nuclear Fusion, 27, No. 4: 619-688 (1987).

33. G. DELL'ORCO, P.A. DI MAIO, R. GIAMMUSSO, A. MALAVASI, L. SANSONE, A. TINCANI and G. VELLA, Fus. Eng. Des. 81, 169 (2006).

34. G. PIAZZA, A. ERBE, R. ROLLI, and O. ROMER, Post-irradiation examinations of $\mathrm{Li}_{4} \mathrm{SiO}_{4}$ pebbles irradiated in the EXOTIC-8 experiment, Jour. of Nuc. Mat. 329-333, 1260 (2004).

35. L. MAGIELSEN, "LIBRETTO $4 / 1$ and 4/2 design and safety report," NRG report 66792, October 2005. www-pub.iaea.org/mtcd/meetings/fec2006/ft_p5-28.pdf 
36. H. HEGEMAN, H. J. VAN DER LAAN, K. BEEMSTERBOER, S. KAMER, B. PIJLGROMS, "Status of the high fluence irradiation of ceramic pebbles in the HICU project," Proceedings of CBBI-13, Santa Barbara, December 2005. wwwpub.iaea.org/mtcd/meetings/fec2006/ft_p5-28.pdf

37. M. ENOEDA, M. AKIBA, and S. KONISHI, "JA Position to TBM Program and Water Cooled Solid Breeder TBM Progress toward Milestones," a presentation to the 20th Test Blanket Working Group, 5-7 November, 2008, Aix-en-Province, France

38. B. BADGER, F. ARENDT, H.M. ATTAYA, K. AUDENAERDE, H. AVCI, et al., "TASKA: Tandem Spiegelmaschine Karlsruhe," University of Wisconsin Fusion Technology Institute Report UWFDM-500, Kernforschungszentrum Karlsruhe Report KfK-3311, Fusion Power Associates Report FPA-82-1 (1982).

39. T.H. BATZER, R.H. BULMER, J.N. DOGGETT, A.I. GOLDNER, J.A. KERNS, et al., “A Tandem Mirror Technology Demonstration Facility," Lawrence Livermore National Laboratory Report UCID-19328 (1983).

40. B. BADGER, F. ARENDT, E. BORIE, M.L. CORRADINI, H.G. DITTRICH, et al., “TASKA-M: A Low Cost, Near Term Tandem Mirror Device for Fusion Technology Testing," Fusion Power Associates Report FPA-83-7, Kernforschungszentrum Karlsruhe Report KfK-3680, University of Wisconsin Fusion Technology Institute Report UWFDM-600 (1983).

41. D. P. GRUBB, et al., Thermal Barrier Production and Identification in a Tandem Mirror”, Phys. Rev. Lett. 53, 783 (1984). 
42. G.I DIMOV, V.V. ZAKAIDAKOV, and M.E. KISHINEVSKY, "Thermonuclear Confinement with Twin Mirror Systems," Fiz. Plasmy 2, 326 (1976).

43. T.K. FOWLER and B.G. LOGAN, "The Tandem Mirror Reactor," Comments on Plasma Physics and Controlled Fusion 2, 167 (1977).

44. D.E. BALDWIN and B.G. LOGAN, "Improved Tandem Mirror Fusion Reactor," Physical Review Letters 43, 1318 (1979).

45. T.C. SIMONEN, S.L. ALLEN, T.A. CASPER, J.F. CLAUSER, C.A. CLOWER, et al., "Operation of the Tandem-Mirror Plasma Experiment with Skew Neutral-Beam Injection," Physical Review Letters 50, 1668 (1983).

46. R. J. BURKE and J. J. HOLMES, “FMIT - Status update,” J. of Nuclear Materials 133, 869 (1985); R. J. BURKE, D. L. JOHNSON, and L. L. CARTER, “Multiple uses of an upgraded FMIT facility," IEEE Transactions on Nuclear Science 32, 3347 (1985).

47. F. H. COENSGEN, T. A. CASPER, D. L. CORRELL, C. C. DAMM, A. H. FUTCH, B. G. LOGAN, and A. W. MOLVIK, "High Performance Beam-Plasma Neutron Sources for Fusion Materials Development", Nuclear Science and Engineering 106, 138 (1990).

48. F. H. COENSGEN, T. A. CASPER, D. L. CORRELL, C. C. DAMM, A. H. FUTCH, B. G. LOGAN, A. W. MOLVIK, and C. E. WALTER, "Beam Plasma Neutron Sources Based on Beam-Driven Mirror”, Journal of Fusion Energy 8, 237 (1989).

49. F. H. COENSGEN, T. A. CASPER, D. L. CORRELL, C. C. DAMM, A. H. FUTCH, and A. W. MOLVIK, "Physics data base for the Beam Plasma Neutron Source, 
(BPNS)," Presented at Workshop on Physics of alternative Magnetic Confinement Schemes, Varenna Italy, LLNL report UCRL-JC-103736 (1990).

50. A. W. MOLVIK, "Impurity radiation from a beam-plasma neutron source," Nuclear Fusion 35, 1247 (1995).

51. B. G. LOGAN, J. F. CLAUSER, F. H. COENSGEN, D. L. CORRELL, W. F. CUMMINS, C. GORMEZANO, A. W. MOLVIK, W. E. NEXSEN, T. C. SIMONEN, B. W. STALLARD, and W. C. TURNER, "High-beta, Gas-stabilized, Mirror-confined plasma,” Phys. Rev. Lett. 37, 1468 (1976).

52. D. D. RYUTOV, D. E. BALDWIN, E. B. HOOPER, and K. I. THOMASSEN.“A high-flux source of fusion neutrons for material and component testing”, J. Fusion Energy, 17, 253 (1998).

53. M. C. VELLA, W. S. COOPER, P. A. PINCOSY, R. V. PYLE, P. D. WEBER, and R. P. WELLS, "Development testing of the U.S. common long pulse source at 120 keV,” Rev. Sci. Instrum. 59, 2357 (1988).

54. J. KIM, R. W. CALLIS, A. P. COLLERAINE, et al., Performance of the DIIID neutral beam injection system," Proc. $12^{\text {th }}$ Symposium on fusion engineering, IEEE (1987), p. 290.

55. R. M. HONG, "Review of Neutral Beam Operating Experience At the DIII-D National Fusion Research Facility," presented at DTNS Workshop, LBNL, March 12, 2009. http://www.mfescience.org/mfedocs/WORKSHOP_Dynamic\%20Trap.pdf 
56. L. R. GRISHAM, O. N. BOWEN, F. DAHLGREN, et al., "Long pulse neutral beam system for the Tokamak Physics Experiment," Fus. Engineering and Design 26, 425 (1995).

57. J. MILNES, D. CIRIC, M. FORNER, S. GEE, et al, "Hypervapotron design for the long pulse upgrades on MAST NBI,” Proc. Symposium on Fusion Engineering, San Diego, CA, 14-17 Oct. 2003, IEEE 2004, p. 478.

58. H. GRUNLOH, J. L. BUSATH, R. W. CALLIS, H. K. CHIU, et al., "Fabrication and Repair of Ion Source Components in the $80 \mathrm{keV}$ Neutral Beam Lines for DIII-D”, Proc. Symposium on Fusion Engineering, San Diego, CA, 14-17 Oct. 2003, IEEE 2004, p. 482.

59. A. W. MOLVIK, R. H. MUNGER, T. J. DUFFY, and D. L. CORRELL, “Geometrically focused neutral beam accelerators," Rev. Sci. Instrum. 52, 965 (1981).

60. V. V. KORSHAKOV, V. G. KRASNOPEROV.V. P. MURATOV, A. A. IVANOV, and YU. A. TSIDULKO, "The electromagnet system of the neutron source based on the Gas Dynamic Trap concept," Plasma Devices and Operations 5, 181 (1997).

61. B. V. ROBOUCH, et al., Fusion Sci. \& Tech. 41, 44 (2002).

62. B. V. ROBOUCH, V. I. VOLOSOV, A. A. IVANOV, YU. A. TSIDULKO, and L. INGROSSO, "Novosibirsk GDT-NS fusion material irradiation facility: Neutronic characteristics and potentialities," Fusion Technology. 35 (1T), 228-232, 1999 Jan.

63. B. V. ROBOUCH, V. I. VOLOSOV, A. A. IVANOV, YU. A. TSIDULKO, Y. N. ZOUEV, L. INGROSSO, and J. S. BRZOSKO, "Neutronic characteristics of the 
Novosibirsk GDT-NS fusion material irradiation facility," Fusion Technology. 41, 44 (2002).

64. T. KIOSHI, M. KOSUGE, K. INONE, and N. MAEDA, IEEE Trans. Magn. 32, 2478 (1997).

65. K. WATANABE, S. AWAJI, et al., IEEE Trans. Magn. 32, 2470 (1997).

66. J. MILLER, Y. EYSSA, and S. PRESTEMON, "Target-Solenoid system design,” FNAL Meeting 15 Feb. 2000; extracted slides presented at the Workshop to “Assess The Mission and Technology of a Gas Dynamic Trap Neutron Source for Fusion Material and Component Testing and Qualification," LBNL, Berkeley, CA, March 12, 2009. http://www.mfescience.org/mfedocs/WORKSHOP_Dynamic\%20Trap.pdf

67. N. MARTOVETSKY, M. TAKAYASU, J. MINERVINI, T. ISONO, M. SUGIMOTO, et al., "Test of the ITER Insert and Central Solenoid Model Coil," IEEE Transactions on Applied Superconductivity 13, 1441 (2003).

68. J. F. BRIESMEISTER, editor, "MCNP-A General Monte Carlo Code for Neutron and Photon Transport,” Los Alamos National Laboratory Report LA-7396-MA.

69. P. A. BAGRYANSKY, A. A. IVANOV, E. P. KRUGLYAKOV, A. M. KUDRYAVTSEV, YU. A. TSIDULKO, A. V. ANDRIYASH, A. L. LUKIN, and YU. N. ZOUEV, "Gas dynamic trap as high power $14 \mathrm{MeV}$ neutron source," Fusion Engineering and Design 70, 13 (2004). Fig. 13. 
aparticipants in Workshop: R. Bulmer (LLNL*), A. Chargin (LLNL*), J. Doggett (LLNL*), K. Fowler (LLNL/UCB*), R. Hong (GA), T. Intrator (LANL), A. Ivanov (BINP -Russia), J. Kulcinski (U. Wisconsin), G. Logan (LBNL), A. Molvik (LLNL/LBNL*), D. Ryutov (BINP/LLNL), T. Simonen (LLNL/GA*), K. Thomassen (LLNL*), S. Willms (LANL- by phone), B. Wirth (UCB), A. Ying (UCLA)

${ }^{b}$ Contributors to Section II: B.D. Wirth**, R.J. Kurtz ${ }^{1}$, G.R. Odette ${ }^{2}$, and S.J. Zinkle ${ }^{3)}$ *University of California, Berkeley, Berkeley, CA USA 94720-1730.

${ }^{1}$ Pacific Northwest National Laboratory, Richland, WA

${ }^{2}$ Department of Mechanical and Environmental Engineering, University of California, Santa Barbara, Santa Barbara, CA USA 93106

${ }^{3}$ Oak Ridge National Laboratory, Oak Ridge, TN USA 
TABLE I. - Requirements for a fusion materials neutron source, as modified from Ref. [28].

\begin{tabular}{|l|l|}
\hline $\begin{array}{l}\text { Neutron flux/Volume } \\
\text { Requirements }\end{array}$ & $\begin{array}{l}\text { Equivalent to } 2 \mathrm{MW} / \mathrm{m}^{2} \text { in } 0.5 \mathrm{~L} \text { Volume (Note, } 1 \mathrm{MW} / \mathrm{m}^{2} \\
=4.5 \times 10^{17} \mathrm{n} /\left(\mathrm{m}^{2}-\mathrm{s}\right) \text { at } \mathrm{E}=14 \mathrm{MeV}, \text { which is equivalent to } \\
\left.3 \times 10^{-7} \mathrm{dpa} / \mathrm{s} \text { in } \mathrm{Fe}\right)\end{array}$ \\
\hline Neutron spectrum & $\begin{array}{l}\text { - Simulate first wall fusion reactor spectrum as close as } \\
\text { possible } \\
\text { Criteria include primary recoil spectrum and } \mathrm{He} / \mathrm{H} \\
\text { transmutant production }(\mathrm{e} . \mathrm{g} ., \approx 10 \text { appm } \mathrm{He} / \mathrm{dpa} \text { in } \mathrm{Fe})\end{array}$ \\
\hline $\begin{array}{l}\text { Neutron fluence } \\
\text { accumulation }\end{array}$ & DEMO-relevant fluences of $150 \mathrm{dpa}$ in a few years \\
\hline Neutron flux gradient & $\leq 20 \% / \mathrm{cm}$ \\
\hline Machine availability & $>70 \%$ to provide quasi-continuous operation \\
\hline
\end{tabular}


TABLE II. Example DEMO Candidate Blanket Concepts.

\begin{tabular}{|l|c|l|}
\hline \multicolumn{1}{|c|}{ Concept } & Acronym & \multicolumn{1}{c|}{ Materials } \\
\hline $\begin{array}{l}\text { Helium-cooled } \\
\text { ceramic breeder }\end{array}$ & $\mathrm{HCCB}$ & $\begin{array}{l}\text { - RAFS structure } \\
\text { - Be multiplier, ceramic breeder }\left(\mathrm{Li}_{2} \mathrm{TiO}_{3}, \mathrm{Li}_{4} \mathrm{SiO}_{4}, \mathrm{Li}_{2} \mathrm{O}\right) \\
\text { - Helium coolant and purge }\end{array}$ \\
\hline $\begin{array}{l}\text { Water-cooled ceramic } \\
\text { breeder }\end{array}$ & WCCB & $\begin{array}{l}\text { - RAFS structure } \\
\text { - Be multiplier, ceramic breeder }\left(\mathrm{Li}_{2} \mathrm{TiO}_{3}, \mathrm{Li}_{2} \mathrm{O}\right) \\
\text { - Water coolant, He purge }\end{array}$ \\
\hline $\begin{array}{l}\text { Helium-cooled Lead- } \\
\text { Lithium }\end{array}$ & HCLL & $\begin{array}{l}\text { - RAFS structure } \\
\text { - Molten Pb-17Li breeder/multiplier } \\
\text { - Helium coolant }\end{array}$ \\
\hline $\begin{array}{l}\text { Dual-coolant Lead- } \\
\text { Lithium }\end{array}$ & DCLL & $\begin{array}{l}\text { - RAFS structure } \\
\text { - SiC flow channel inserts } \\
\text { - Molten Pb-17Li breeder/coolant } \\
\text { - Helium coolant }\end{array}$ \\
\hline
\end{tabular}


TABLE III. Design parameters for TASKA, TDF, and TASKA-M.

\begin{tabular}{|c|c|c|c|}
\hline Parameter & TASKA & TDF & TASKA-M \\
\hline Publication Year & 1982 & 1983 & 1984 \\
\hline Type & $\begin{array}{c}\text { Tandem mirror } \\
\text { with separate } \\
\text { thermal barrier } \\
\text { and yin-yang } \\
\text { ion-plug cells }\end{array}$ & $\begin{array}{c}\text { Tandem mirror } \\
\text { with combined } \\
\text { thermal barrier } \\
\text { and yin-yang } \\
\text { ion-plug cells }\end{array}$ & $\begin{array}{c}\text { Axisymmetric } \\
\text { central cell with } \\
\text { sloshing ions plus } \\
\text { yin-yang MHD } \\
\text { anchors but no } \\
\text { thermal barrier or } \\
\text { ion plug }\end{array}$ \\
\hline $\begin{array}{c}\text { Maximum Neutron Wall } \\
\text { Load, MW/m }\end{array}$ & 1.5 & 1.4 & 1.3 \\
\hline $\begin{array}{c}\text { Average Neutron Wall } \\
\text { Load, MW/m }\end{array}$ & 1.5 & 1.4 & 0.6 \\
\hline $\begin{array}{c}\text { Test Zone Surface } \\
\text { Area, m }\end{array}$ & 7.8 & 8 & 3.6 \\
\hline Fusion Power, MW & 86 & 20 & 7 \\
\hline Input Power, MW & 117 & 51 & 40 \\
\hline Input systems & NB/ICRF/ECRF & NB/ECRF & NB/ICRF \\
\hline Total Length, m & 60 & 24 & 24 \\
\hline $\begin{array}{c}\text { Central (Test) Cell } \\
\text { Length, m }\end{array}$ & 19 & 8 & 5 \\
\hline Maximum B Field, T & 20 & 15 & 17.5 \\
\hline $\begin{array}{c}\text { Central Cell Beta } \\
\text { (plasma/B-field }\end{array}$ & 0.5 & 0.24 & 0.30 \\
\hline
\end{tabular}




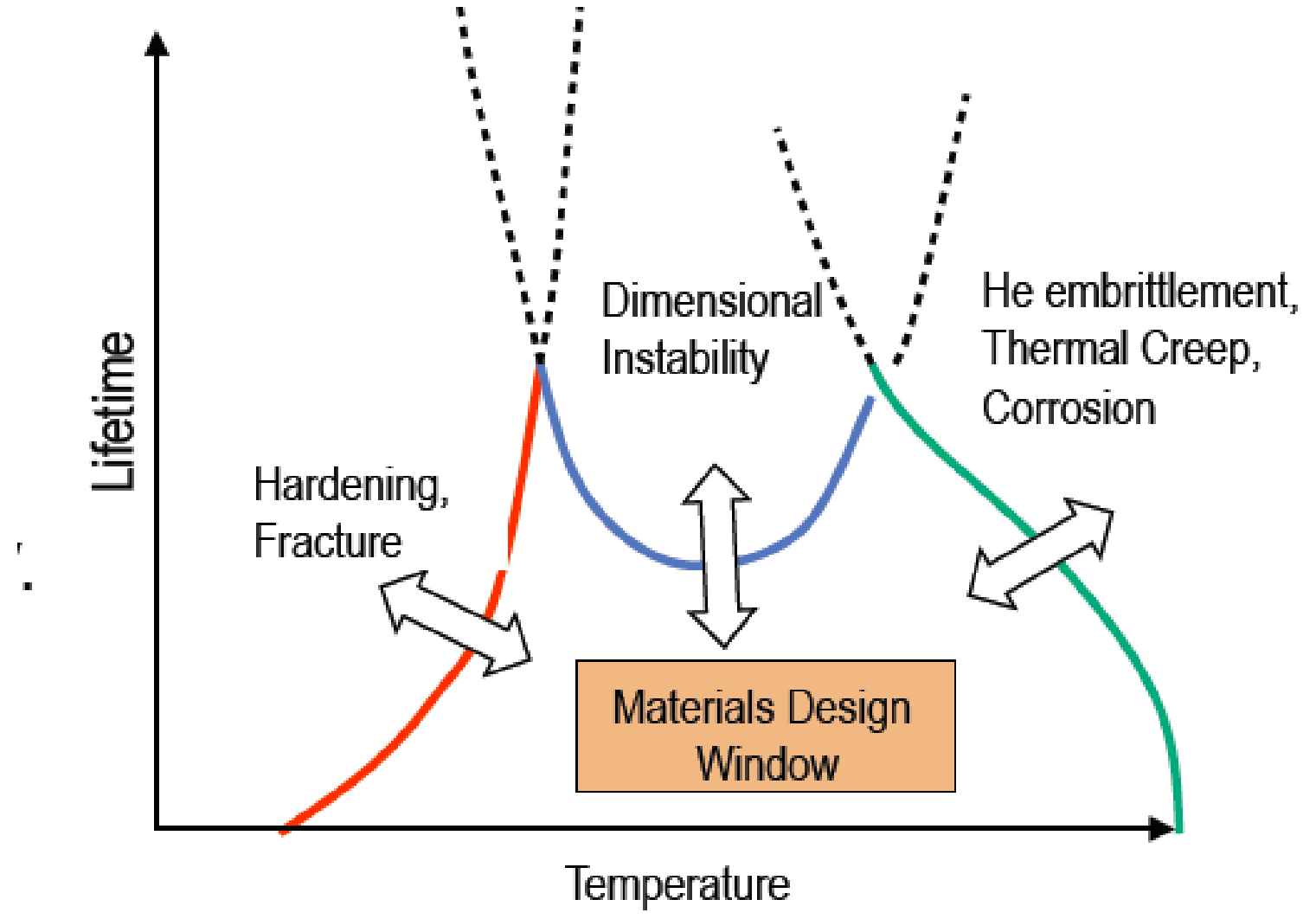

Fig. 1 


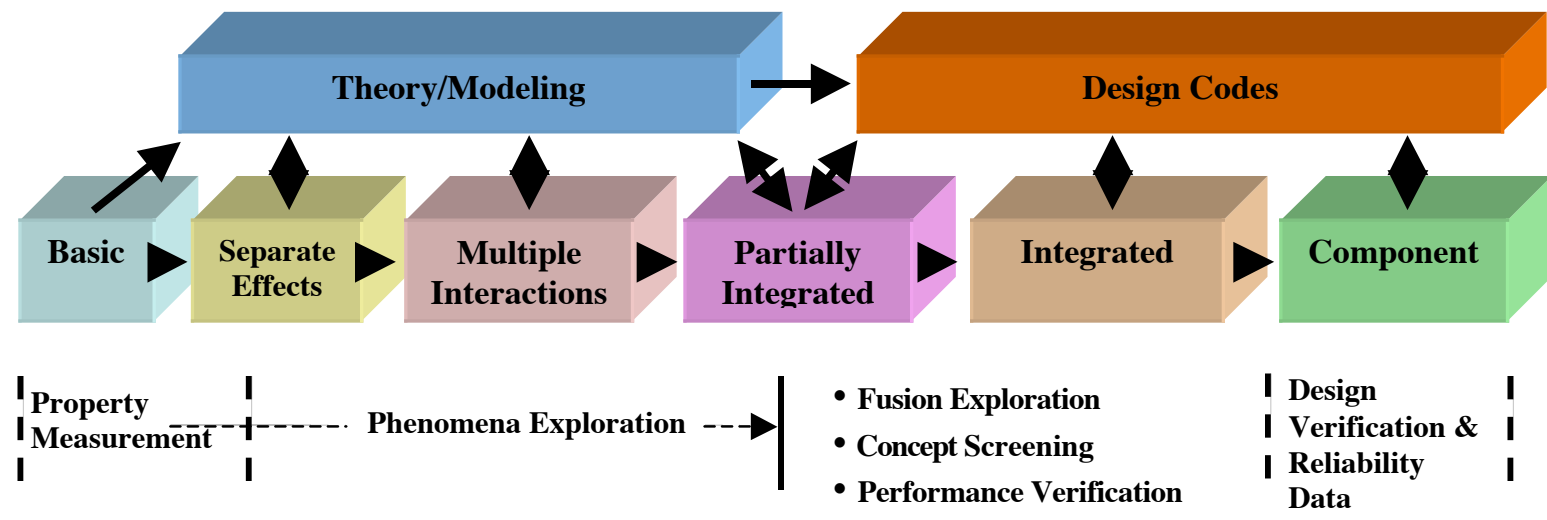

Fig. 2. 

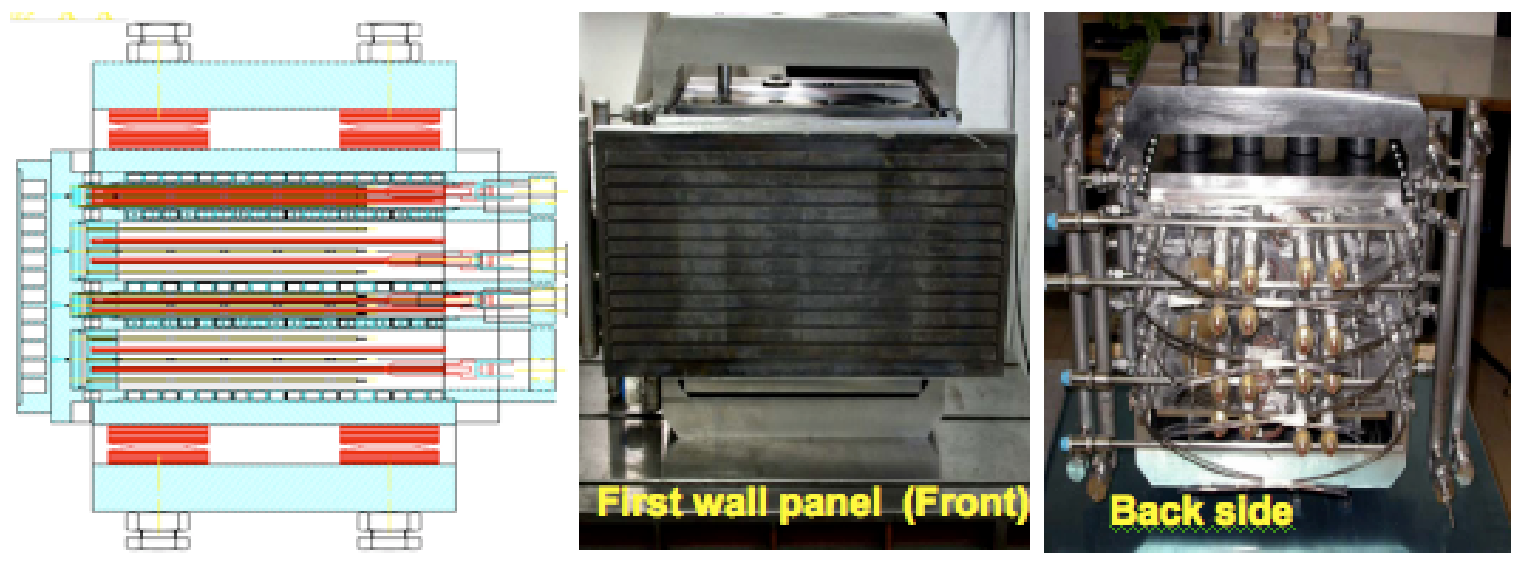

Fig. 3. 

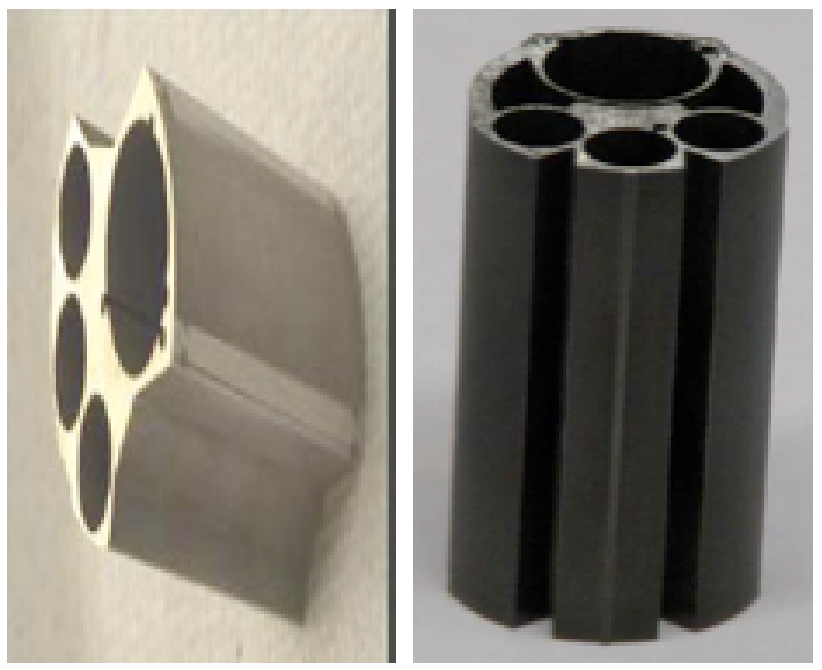

Fig. 4. 

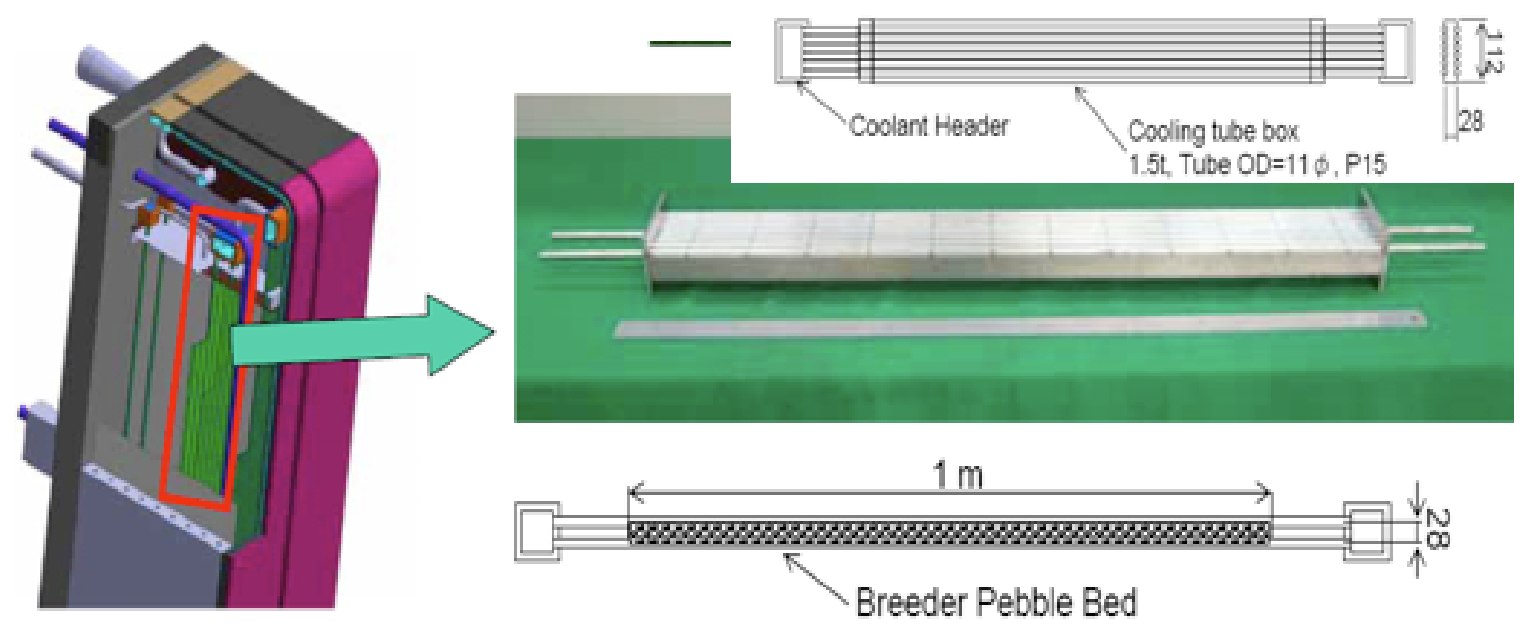

Fig. 5. 


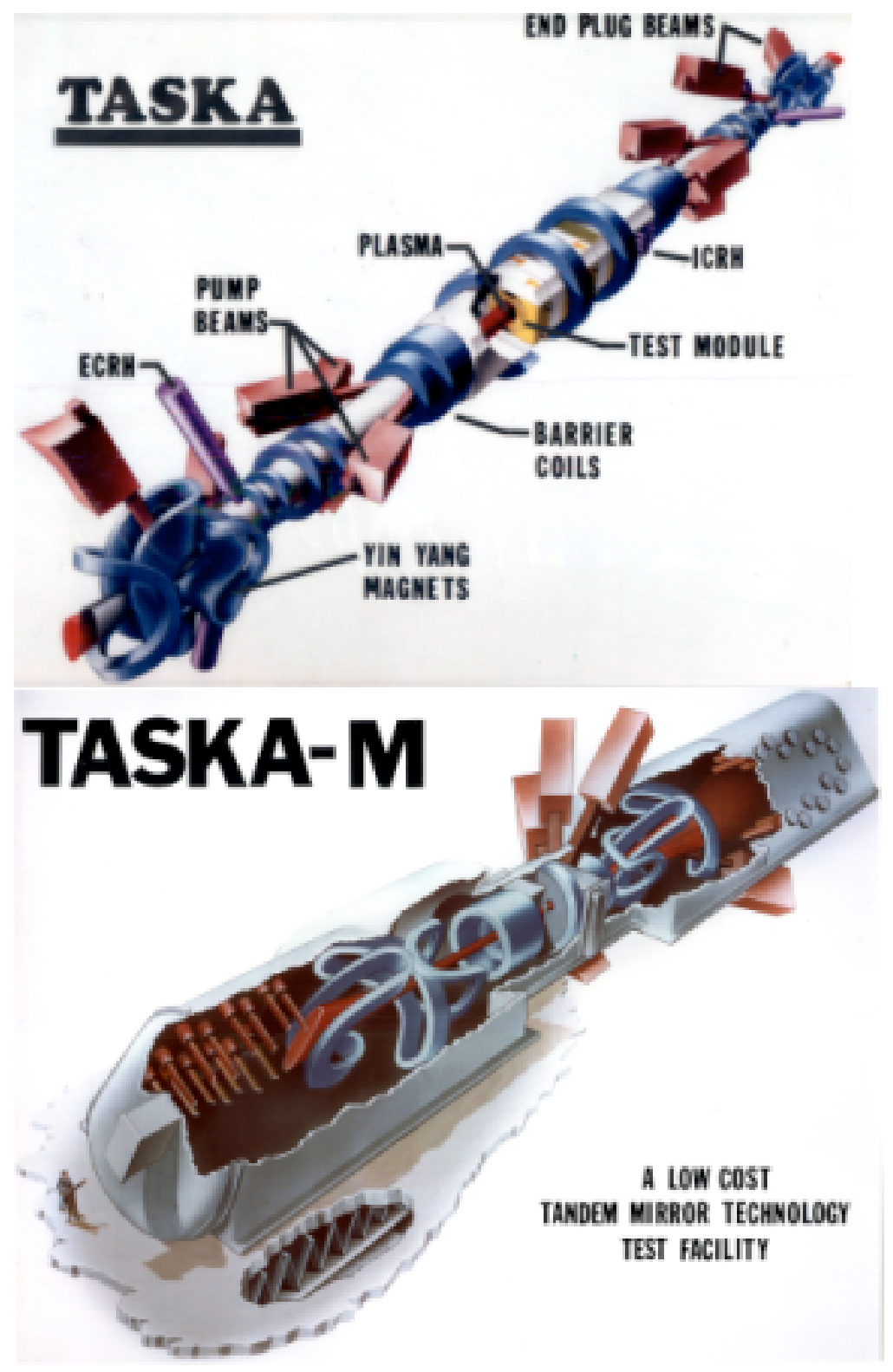

Fig. $6(a, b)$ 


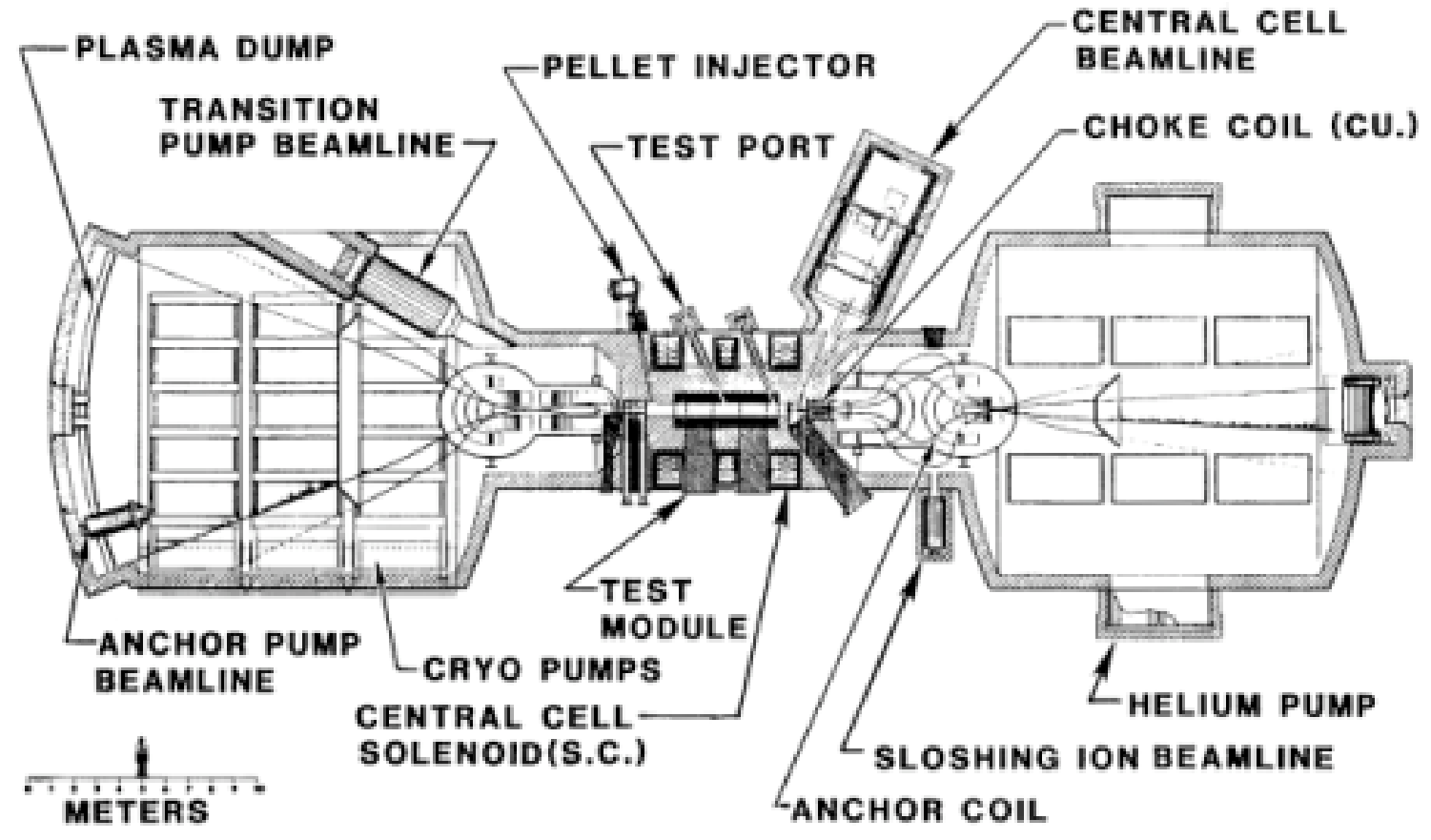

Fig. 6 (c) 

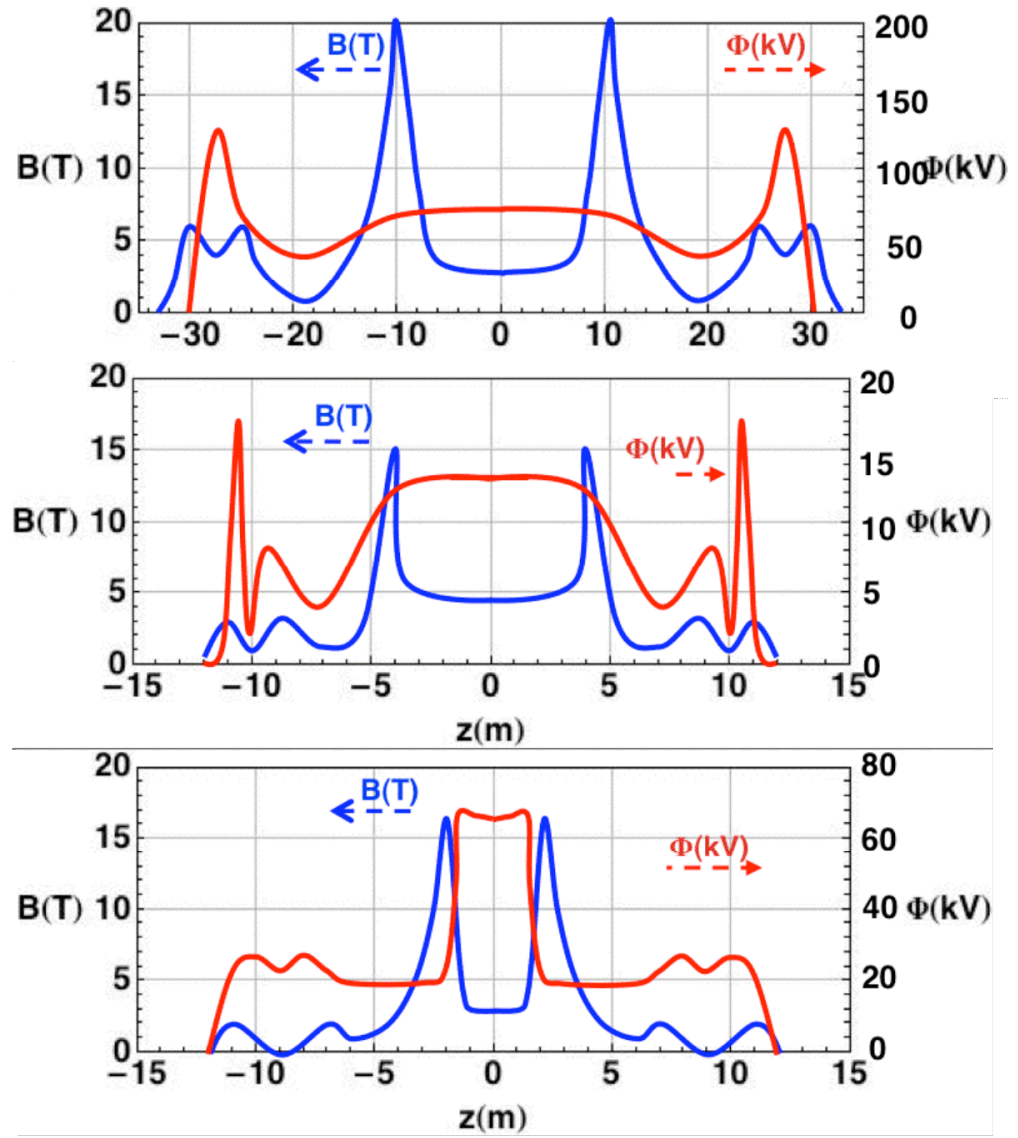

Fig. 7 (a, b, c). 


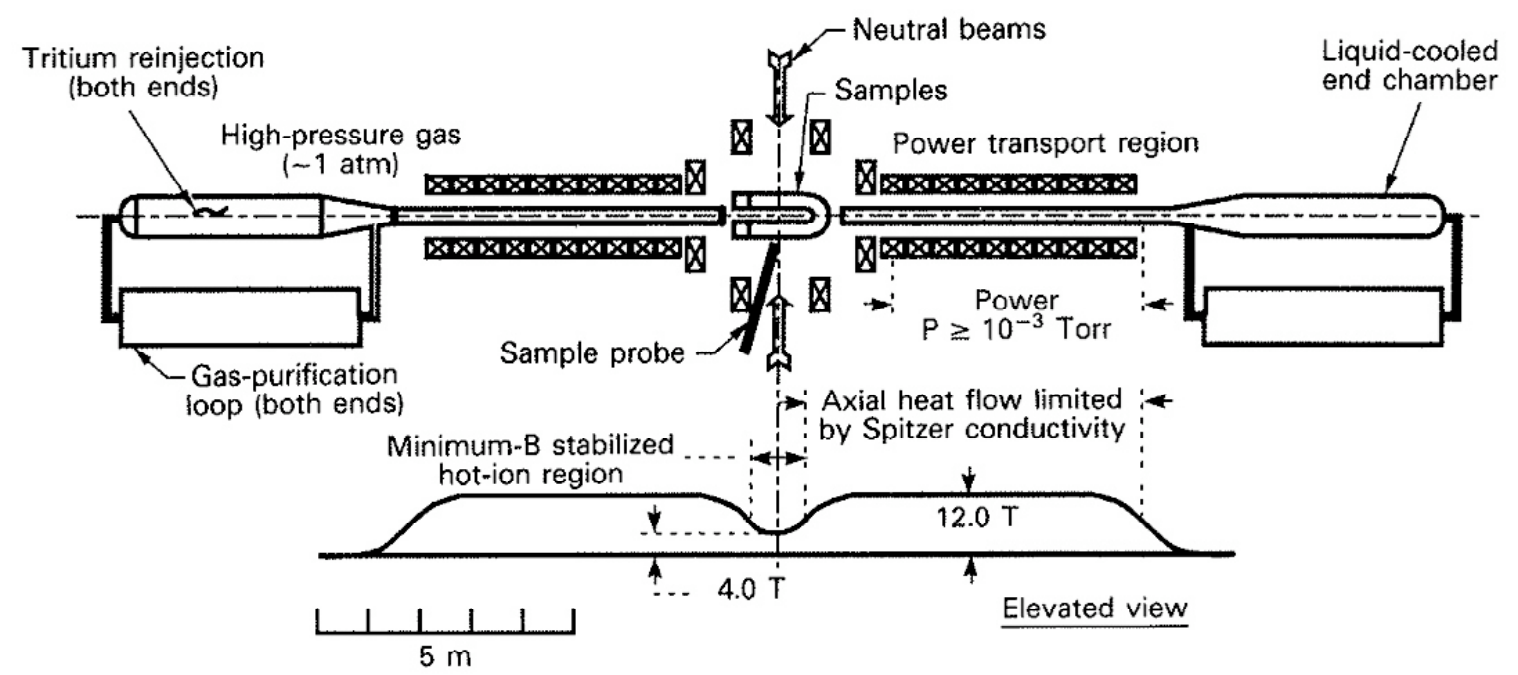

Fig. 8 . 


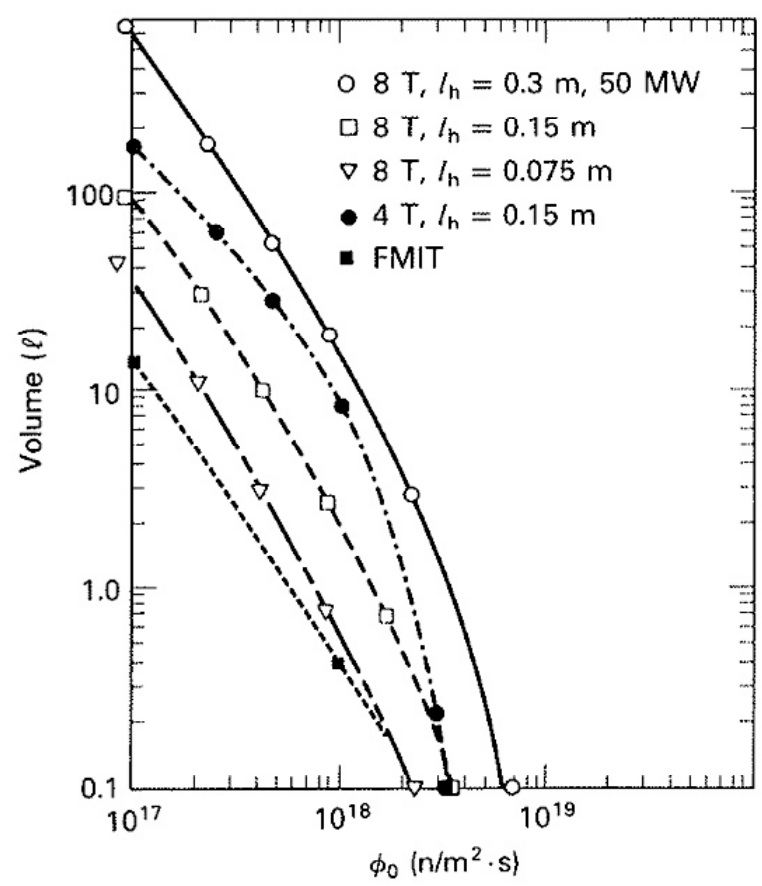

Fig. 9. 


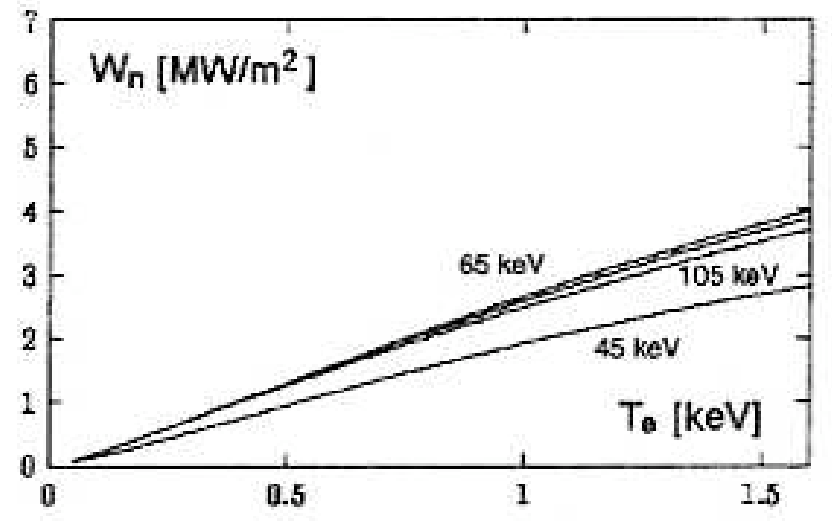

Fig. 10 . 


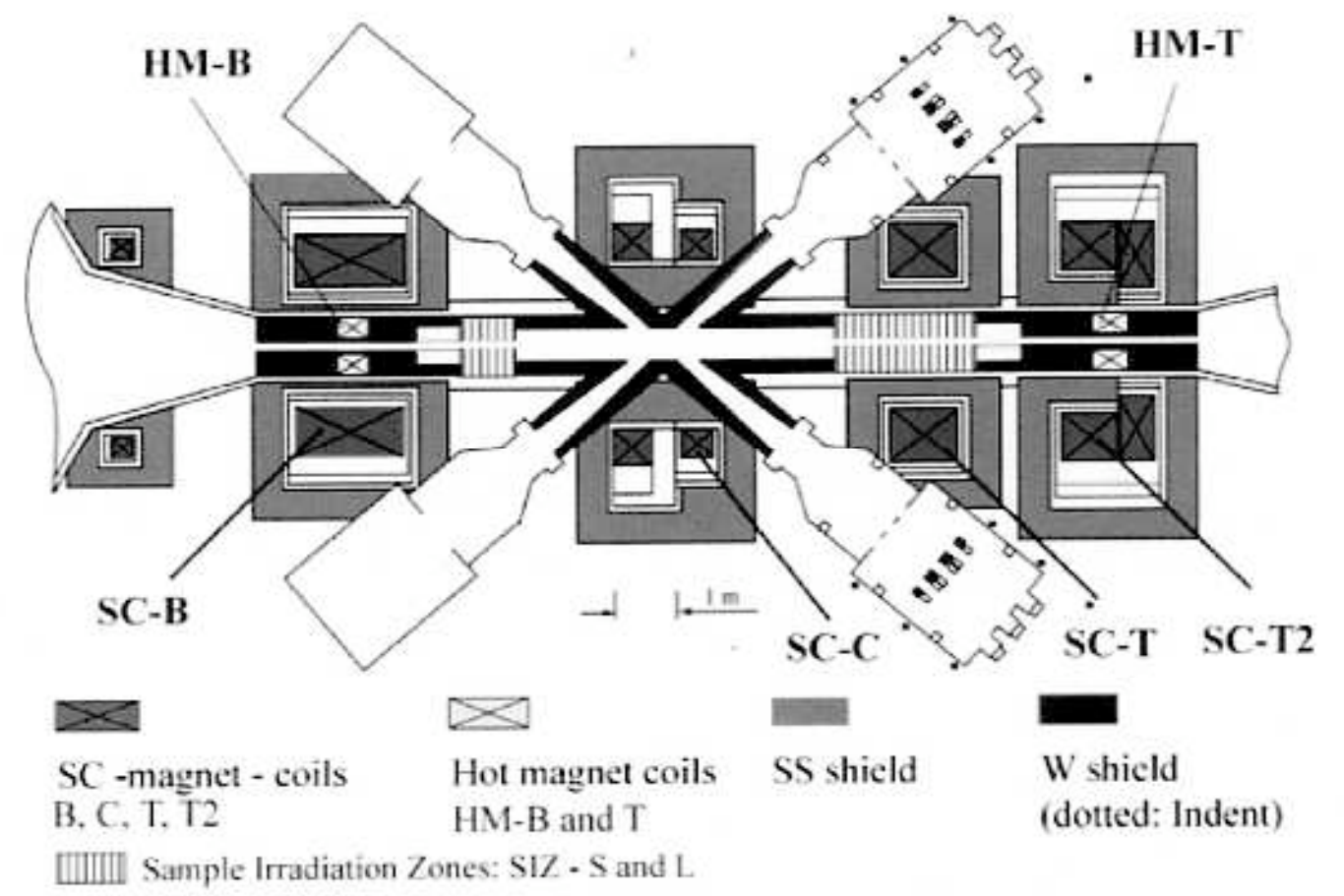

Fig. 11. 


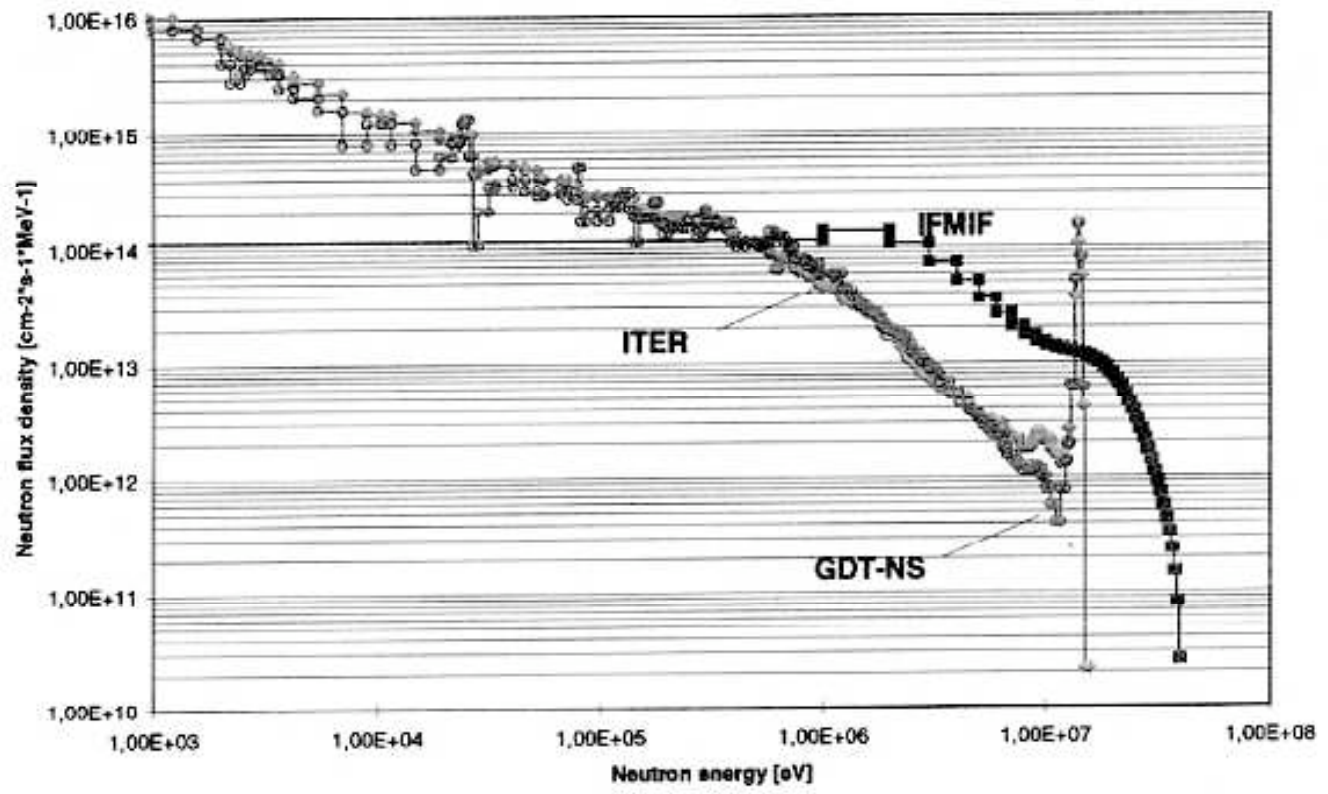

Fig. 12. 


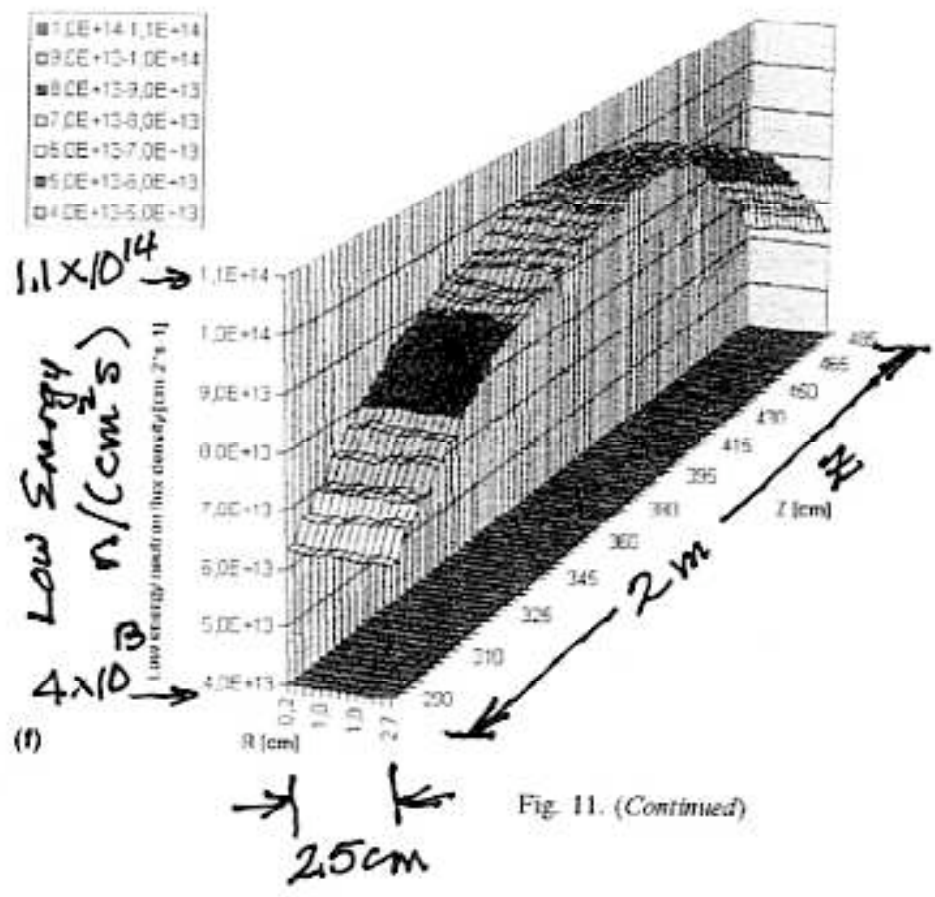

Fig. 13. 

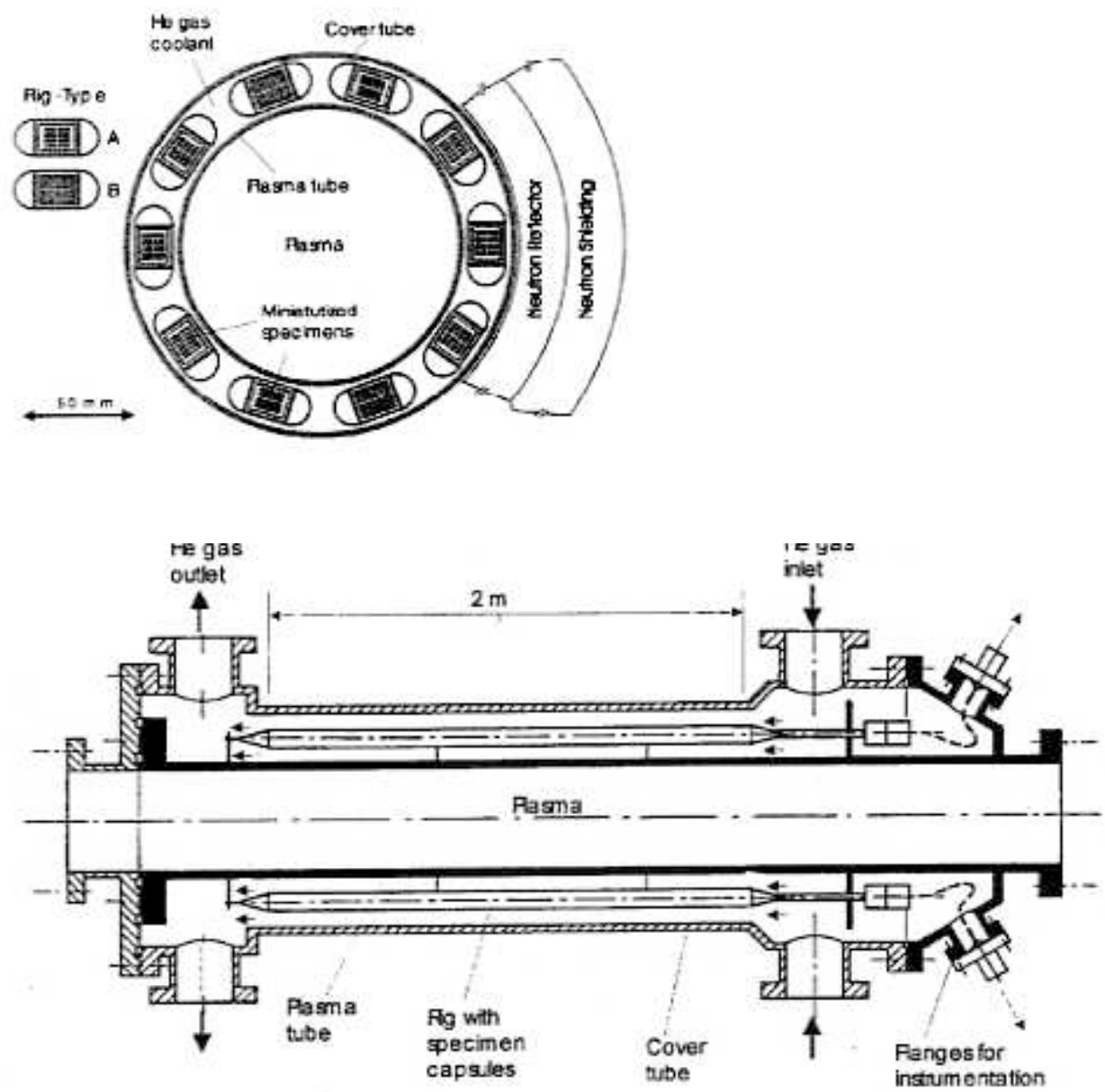

Fig. 14 (a, b). 


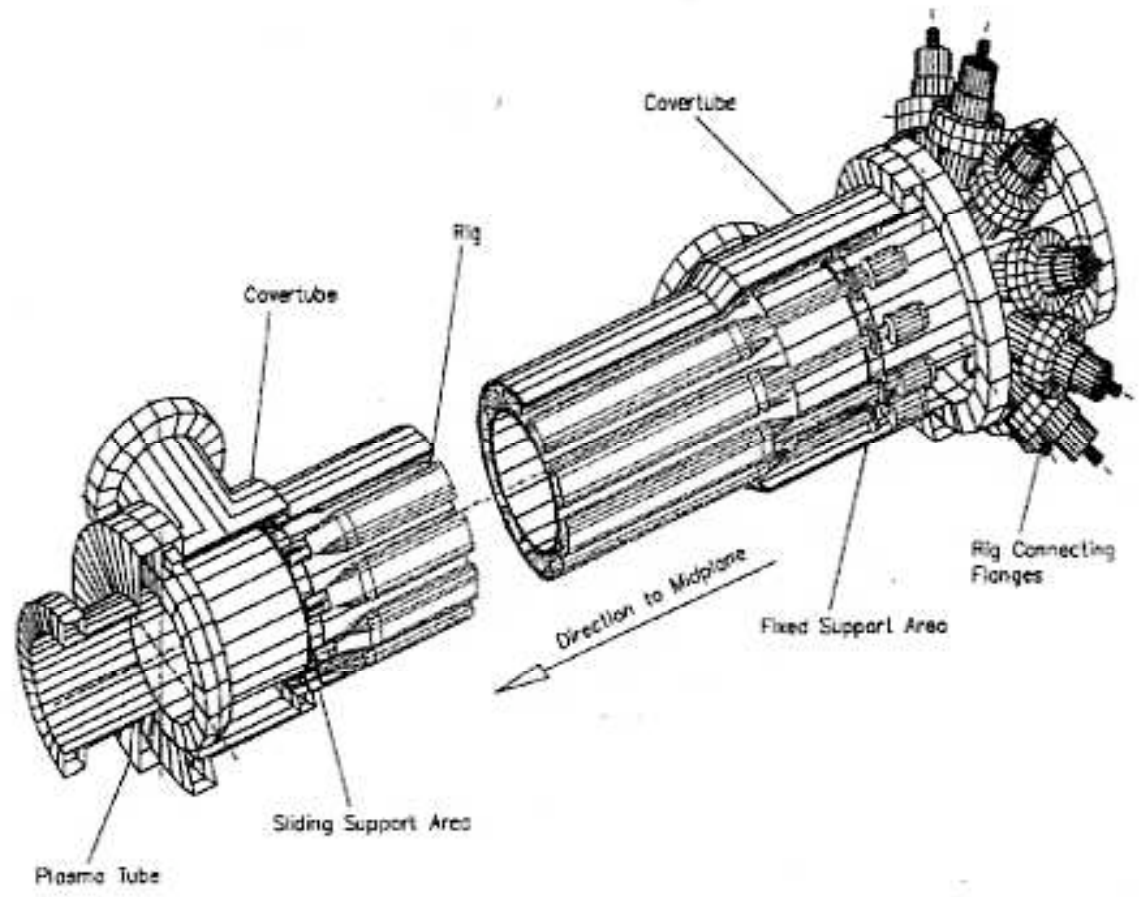

Fig. 14c. 


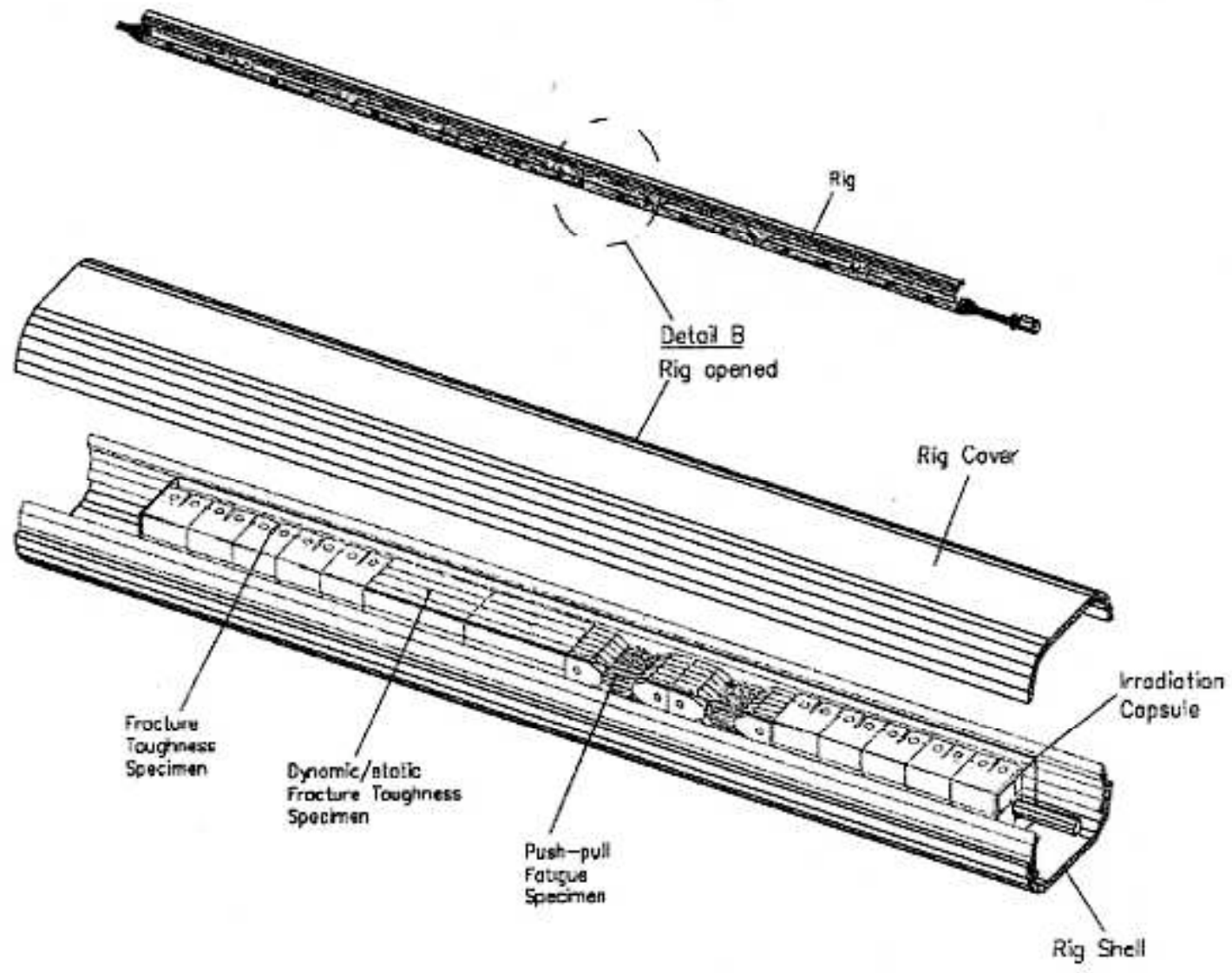

Fig. 14 d. 


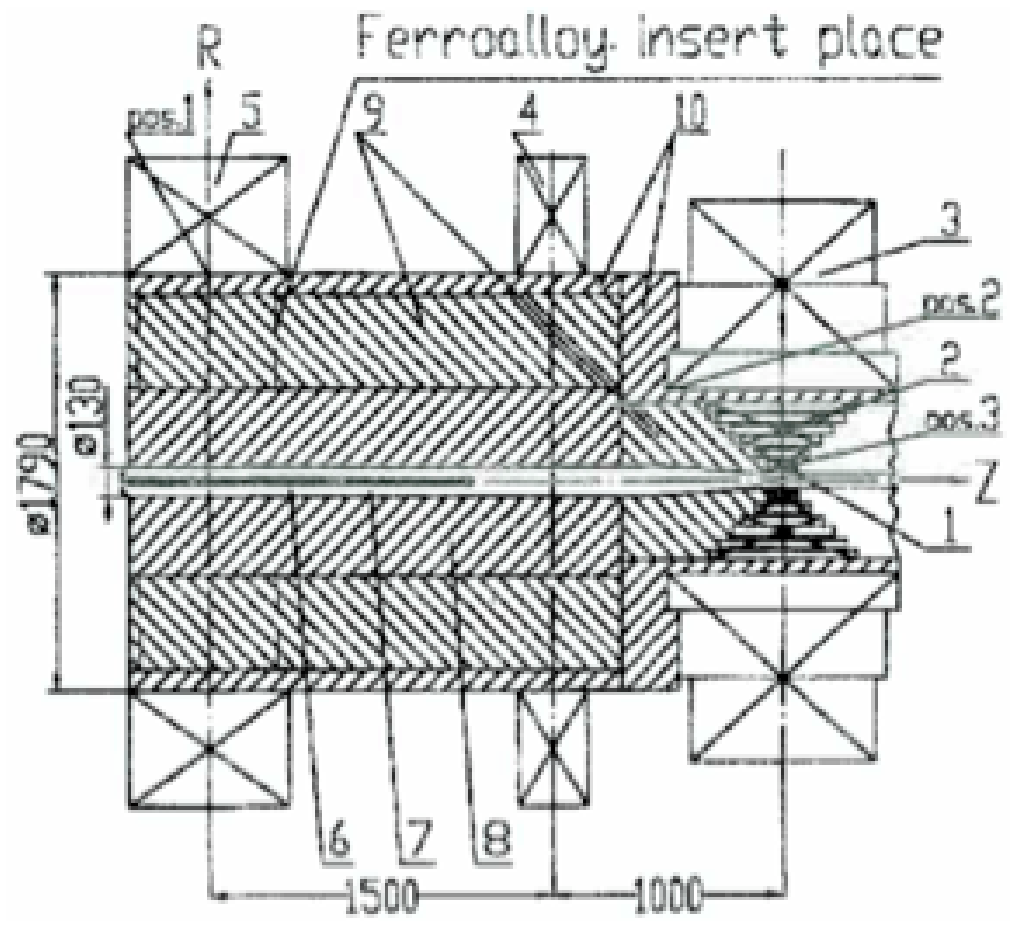

Fig. 15. 


\section{FIGURE CAPTIONS}

Figure 1 - Illustration of the materials design window for the fusion energy environment, as a function of temperature. At low temperature, materials component lifetime is limited by irradiation hardening and fast fracture, while dimensional instability or swelling may limit performance at intermediate temperatures. Increasing temperature alleviates these degradation modes, but component lifetime is now limited by thermal creep, environmental degradation (e.g., corrosion) and He embrittlement. It is important to note that limited data exists for very high concentrations of transmutant He in current candidate fusion materials and thus, it is possible that high He concentrations may further narrow or even close the design window.

Fig. 2. Types of experiments for fusion blanket material systems.

Fig. 3. The HEXCALIBER test article for solid breeder blanket pebble bed thermomechanics experiments at ENEA Brasimone ${ }^{33}$.

Fig. 4. Two of the three kinds of drums used in HICU experiments with $4 \times 42 \mathrm{~mm}$ or $9 \times$ $20 \mathrm{~mm}$ tubes.

Fig. 5. A blanket submodule test vehicle with weld joints and pipes can provide many useful engineering data for blanket designs and fabrications. The test article is based on the JAEA water-cooled solid breeder blanket design ${ }^{37}$. 
Fig. 6. (a) TASKA, (b) TASKA-M, and (c) TDF main features.

Fig. 7. Axial profiles of magnetic field (B) and electrostatic potential ( $\Phi)$ for (a) TASKA, (b) TDF, and (c) TASKA-M.

Fig. 8. Schematic of beam-plasma neutron source. The central section of the vacuum chamber and the neutron shielding of superconducting magnets are not shown.

Fig. 9. Test volumes versus neutron flux for four versions of the BPNS and the FMIT.

Fig. 10. Neutron flux as a function of electron temperature in DTNS.

Fig. 11. Schematic of DTNS showing superconducting and resistive magnets, sample irradiation zones, neutron shielding, and neutral beam injection/dump lines.

Fig. 12. Neutron flux as a function of neutron energy for ITER, the DTNS, and IFMIF.

Fig. 13. DTNS neutron flux density as a function of radius and axial position.

Fig. 14(a,b). DTNS irradiation sample holders with provision for helium gas cooling and instrumentation.

Fig. 14(c,d). DTNS irradiation sample holders with provision for helium gas cooling mechanical stress application, and instrumentation. 
Fig. 15. Design scheme of the radiation shielding of the solenoids in the area of maximum neutron yield. 1 - resistive solenoid with radial water cooling; 2 - resistive solenoid with axial water cooling; $3-5$ - superconducting solenoids; 6 - neutron release area; 7 - plasma; 8 - experimental module; 9 - radiation shielding; 10 - mechanical structures. 


\section{APPENDIX}

A comprehensive list of GDT, and tandem mirror neutron source publications.

\section{A.1 GDT Journal publications}

Andriyash AV. Grebyonkin KF. Emelyanov SA. Zuev YN. Lukin AV. Markelov NN.

Ivanov AA. Kruglyakov EP. "Source of thermonuclear neutrons based on gas dynamic trap - status of conceptual design and alternative applications.” Fusion Engineering \& Design. 41:485-490, 1998 Sep.

Anikeev AV. Bagryanskii PA. Bocharov VN. Deichuli PP. Ivanov AA. Karpushov AN. Maksimov VV. Rogozin AI. Salikova TV. "Measurement of plasma parameters in a gas dynamical confinement system with intense atomic beam injection.” Plasma Physics Reports. 20(2):176-179, 1994 Feb.

Anikeev AV. Bagryansky PA. Ivanov AA. Karpushov AN. Maximov VV. Murakhtin SV. "Hot-ion plasma with high energy content in a gas-dynamic trap. "Plasma Physics Reports. 25(6):451-460, 1999 Jun.

Anikeev AV. Bagryansky PA. Ivanov AA. Karpushov AN. Korepanov SA. Maximov VV. Murakhtin SV. Smirnov AY. Noack K. Otto G. "Fast ion relaxation and confinement in the gas dynamic trap", Nuclear Fusion 40(4):753-765, 2000 Apr.

Anikeev AV. Bagryansky PA. Deichuli PP. Ivanov AA. Karpushov AN. Maximov VV. Podminogin AA. Stupishin NV. Tsidulko YA. Observation of magnetohydrodynamic 
stability limit in a cusp-anchored gas-dynamic trap. Physics of Plasmas. 4(2):347-354, 1997 Feb.

Anikeev AV. Bagryansky PA. Ivanov AA. Kotelnikov IA. "Measurements of plasma equilibrium response to external multipole magnetic fields in an axisymmetric mirror." Plasma Physics \& Controlled Fusion. 37(11):1239-1247, 1995 Nov.

Anikeev AV. Bagryansky PA. Ivanov AA. Kuzmin S.V., Salikova T.V. "Experimental observation on non-MHD effects in the curvature-driven flute instability." Plasma Physics and Controlled Fusion, 34, 1185 (1992)

Anikeev AV. Bagryansky PA. Kuznetsov GI. Stupishin NV. "Longitudinal confinement of particles and energy in a gas-dynamic trap.” Plasma Physics Reports. 25(10):775-782, 1999 Oct

Anikeev AV. Bagryansky PA. Ivanov AA. Kuznetsov GI. Stupishin NV. "Longitudinal plasma confinement in the gas dynamic trap. Fusion Technology." 35(1T):126-130, 1999 Jan.

Bagryanskii PA. Bender ED. Ivanov AA. Karpushov AN. Murakhtin SV. Noack K. Krahl S. Collatz S. "Effect of wall conditioning on neutral gas transport in the gas-dynamic confinement system.” Plasma Physics Reports. 23(11):903-910, 1997 Nov.

Bagryansky PA. Bender ED. Ivanov AA. Karpushov AN. Murakhtin SV. Noack K. Krahl S. Collatz S. "Effect of fast Ti-deposition on gas recycling at the first wall and on fast ion losses in the GDT experiment.” Journal of Nuclear Materials. 265(1-2):124-133, 1999 Feb. 
P.A. Bagryansky, A.D. Beklemishev, M.S. Chaschin, E.I. Soldatkina. "Radial electric field and radial currents in the Gas-Dynamic Trap.” Fus. Sci. Techn., 51, 337 (2007).

P.A. Bagryansky, A.D. Beklemishev, E.I. Soldatkina. "Influence of radial electric field on high-beta plasma confinement in the Gas-Dynamic Trap.” Fus. Sci. Techn., 51, 340 (2007).

A.D. Beklemishev. "Shear-flow effects in open traps." In: "Theory of fusion plasmas,” AIP Conference Proceedings 1069, p. 3, 2008.

Berk H.L., Ryutov D.D. "Importance of a mirror based neutron source for the controlled fusion program." Comments on Plasma Physics, 13, 173 (1990)

Berk H.L., Stupakov G.V. "Stability of the gas-dynamic trap.” Phys. Fluids, B3, 440 (1991)

Bobouch et al., Fusion Sci. \& Tech. 41, 44 (2002).

Collatz S. Noack K. "NEUSI - A code for the calculation of neutral particle densities inside the plasma region of the GDT." Fusion Technology. 35(1T):375-378, 1999 Jan.

Davydenko VI. Ivanov AA. Karpushov AN. Rogozin AI. Stupishin NV. Shikhovtsev IV. "Measurements of fast-ion parameters in the gdl device by means of an auxiliary target." Plasma Physics Reports. 23(5):396-399, 1997 May. 
Deichuli PP. Ivanov AA. Stupishin NV. "Measurements of the ambipolar potential profile in the expander da gas-dynamic trap by means of a local gas target." PlasmaPhysics Reports. 24(8):662-666, 1998 Aug.

Fischer U. Moslang A. Ivanov AA. "The gas dynamic trap as neutron source for materials irradiations.” Fusion Technology. 35(1T):160-164, 1999 Jan.

Ivanov AA. Anikeev AV. Bagryansky PA. Bocharov VN. Deichuli PP. Karpushov AN. Maximov VV. Podminogin AA. Rogozin AI. Salikova TV. Tsidulko YA. Experimental study of curvature-driven flute instability in the gas-dynamic trap. Physics of Plasmas. 1(5 Part 2):1529-1535, 1994 May.

Ivanov A.A., Anikeev AV. Bagryansky PA. Bocharov VN., Karpushov AN. Korepanov S.A., Kornilov V.N., Lizunov A.A., Maximov VV., Murakhtin S.V. "High-pressure plasma confinement and stability studies in gas dynamic trap" Trans. Fus. Techn., 39127 (2001)

Ivanov AA. Karpushov AN. Lotov KV. "Gas-Dynamic Trap experiment: Status and perspectives.” Fusion Technology. 35(1T):107-111, 1999 Jan.

Ivanov A.A., Ryutov D.D. "Mirror-based neutron sources for fusion technology studies." Nucl. Sci. and Engineering, 106, 235 (1990)

Ivanov AA. Rogozin AI. “Active corpuscular diagnostics of plasma density profile in gasdynamical confinement system. “ Plasma Physics Reports. 20(2):165-167, 1994 Feb.

Ivanov, A. A., et al., Phys. Rev. Lett 90, 105002 (2003). 
Ivanov A.A., et al., IAEA Geneva, 2008, EX/P5-43.

Kammash T. Lee MJ. "Gasdynamic fusion propulsion system for space exploration. " Journal of Propulsion \& Power. 11(3):544-553, 1995 May-Jun.

Kammash T. Lee MJ. Poston DI. "High-thrust high-specific impulse gasdynamic fusion propulsion system. “ Journal of Propulsion \& Power. 13(3):421-427, 1997 May-Jun.

Kammash T. Galbraith DL. Improved physics model for the gasdynamic mirror fusion propulsion system. Journal of Propulsion \& Power.14(1):24-28, 1998 Jan-Feb.

Karpushov AN. Anikeev AV. Bagryansky PA. Ivanov AA. Korepanov SA. Lizunov AA. Maximov VV. Murakhtin SV. Noack K. Saunichev KN. Energy confinement of the two component plasma in the gas-dynamic trap. Fusion Technology. 35(1T):190-194, 1999 Jan.

Korepanov SA. Bagryansky PA. Deichuli PP. Ivanov AA. Tsidulko YA. The measurement of plasma density profile in GDT using diagnostic injector DINA-5.Fusion Technology. 35(1T):345-348, 1999 Jan.

Korshakov VV. Krasnoperov VG. Ivanov AA. Tsidulko YA. Budker GI. Design of the magnet system for neutron yield zone of the plasma neutron source based on the gasdynamic trap. Fusion Technology. 35(1T):195-199, 1999 Jan.

Kotelnikov I.A., Masliev I.E., Shaikhislamov I.F., Ryutov D.D., Yakovchenko S.G. 
"Flute instability in an open system with injection of intense neutral beams" Sov. J.Plasma Phys., 16, 669 (1990).

Kotelnikov I.A., Roslyakov G.V., Ryutov D.D. "Stabilization of flute perturbations in an axisymmetric open system with instreaming ions.” Sov. J. Plasma Phys., 13, 227 (1985)

Kotelnikov I.A., Ryutov D.D. "Effects of an ambipolar potential in a two-component Gas dynamic confinement system.” Sov. J. Plasma Phys., 11, 655 (1985)

Kruglyakov E.P. "Mirror research at Novosibirsk.” Plasma Physics and Controlled Fusion, 29, 1309 (1987)

Kruglyakov EP. "High power $14 \mathrm{MeV}$ neutron sources for tests of materials..." Fusion Technology. 35(1T):20-29, 1999 Jan.

Kruglyakov E.P. "Modern concepts of high power $14 \mathrm{MeV}$ neutron sources: Status and perspective.” Trans. Fus. Techn., 39, 57 (2001)

Lotov KV. Ivanov AA. "Ballistic bunching of fast ions in a mirror trap", Plasma Physics \& Controlled Fusion. 42(10):1077-1090, 2000 Oct.

Lotov K.V., Ryutov D.D., Weiland J. "Velocity shear effects in the problem of the electron temperature gradient instability induced by conducting end walls". Physica Scripta, .50, $153(1994)$

Mirnov V.V., Ryutov D.D. "Linear gas-dynamic system for plasma confinement," Sov. Tech. Phys. Lett., 5, 279 (1979) 
Murachtin SV. Bagryansky PA. Bender ED. Ivanov AA. Karpushov AN. Noack K. Krahl S. Collatz S. Wall conditioning and neutral gas transport at the GDT facility. Fusion Technology. 35(1T):370-374, 1999 Jan.

Nagornyj V.P., Ryutov D.D., Stupakov G.V. "Flute instability of plasma in a gasdynamic trap.” Nucl. Fusion, 24, 1421 (1984)

Noack K. Otto G. Collatz S. Transport simulations of fast ion and neutral gas dynamics during GDT experiments. Fusion Technology. 35(1T):218-222, 1999 Jan.

Robouch BV. Volosov VI. Ivanov AA. Tsidulko YA. Ingrosso L. Novosibirsk GDT-NS fusion material irradiation facility: Neutronic characteristics and potentialities. Fusion Technology. 35(1T):228-232, 1999 Jan.

Robouch BV. Volosov VI. Ivanov AA. Tsidulko YA. Zouev YN. Ingrosso L. Brzosko JS. Neutronic characteristics of the Novosibirsk GDT-NS fusion material irradiation facility. Fusion Technology. 41(1):44-52, 2002 Jan.

Ryutov D.D. "Physics of open traps.” Plasma Physics and Controlled Fusion, 28, 191(1986) Ryutov D.D. “Mirror type neutron source.” Plasma Physics and Controlled Fusion, 32, 999 (1990)

Ryutov, DD, Baldwin DE, Hooper EB, Thomassen KI.“A high-flux source of fusion neutrons for material and component testing”, J. Fusion Energy, 17, 2531998 Sep. 
Stupakov G.V. “Trapped particle instability in a gas-dynamic trap.” Sov. J. Plasma Phys., $16,275(1990)$

Zhitlukhin A.M., Safronov V.M., Sidnev V.V., Skvortsov Yu.V. "Confinement of the beta 1 plasma in the open trap.” JETP Lett, 39, 247 (1984).

Zuev AA. Ivanov AA. Karpushov AN. Kolesnikov EY. Murakhtin SV. Strogalova SL. "Dynamics of ion heating in a gas-dynamic trap during neutral beam injection", Plasma Physics Reports. 28(4):268-273, 2002 Apr.

\section{A.2. GDT Conference Proceedings}

Anikeev AV. Bagryanskii PA. Deichuli PP. Ivanov AA. Karpushov AN. Maksimov VV., Shikhovtsev, I.V., Stupishin N.V., Tsidulko Yu.A., Voropaev S.G., Murakhtin S.V., Noack K., Kumpf H., Krahl S., Otto G. "Plasma confinement and stability studies in the gas dynamic trap experiemnt.” In: "Fusion Energy 1996”, v.2, 283, Vienna, IAEA (1997)

Bagryansky P.A., Ivanov A.A., Karpushov A.N., Klesov V.V., Kotelnikov I.A., Krasnikov Yu.I., Rogozin A.I., Roslyakov G.V, Tsidulkp Yu.A., Breun R.A., Molvik A.W., Casper T.A. "Experimental MHD stability limit in the gas-dynamic trap." In: “Plasma Physics and Controlled Fusion Research”, v.2, p. 655, Vienna, IAEA (1991).

Bagryansky P.A., Ivanov A.A., Klesov V.V., Kotelnikov I.A., Kozminykh Yu.L., 
Krasnikov Yu.I., Rogozin A.I., Roslyakov G.V.,, Tsidulko I. A. "Experiments on neutral beam injection in a gas-dynamic trap" In: "Plasma Physics and Controlled Fusion Research”, v.2, p. 483, Vienna, IAEA (1989).

Bagryansky P.A., Ivanov A.A., Klesov V.V., Kozminykh Yu.L., Krasnikov Yu.I., Podyminogin A.A., Rogozin A.I., Roslyakov G.V.,, Ryutov D.D. “First experiments on the gas-dynamic trap" In: "Plasma Physics and Controlled Fusion Research", v.3, p. 467, Vienna, IAEA (1987).

Berk H.L., Ryutov D.D., Stupakov G.V., Tsidulko Yu.A. “Instability effects caused by conducting end walls in a plasma on open field lines." In: "Plasma Physics and Controlled Fusion Research”, v.2, p. 289, Vienna, IAEA (1991).

Ivanov, A.A., E.P. Kruglyakov,, Yu.A. Tsidulko, V.I. Volosov, A.V. Andriyash, A.V. Lukin, K.F. Grebenkin, V.G. Krasnoperov, H. Kumpf, K. Noack, V.V. Robouch, S. Bikikmen, S. Cakir, V.V. Mirnov. "Improved version of a mirror-based $14 \mathrm{MeV}$ neutron source.” In: “Fusion Energy 1996”, v.3, 667, Vienna, IAEA (1997)

Ivanov A.A., Anikeev A.V.,Bagryansky P.A., Deichuli P.P., Karpushov A.N. Korepanov S.A., Lizunov A.A., Maximov V.V., Murakhtin S.V., Stupishin N.V., Shikhovtsev I.V., Noack K., Otto G. "Experiments on high-beta plasma confinement in gas dynamic trap" In: “Fusion Energy 1998”, v.3, p. 875, Vienna, IAEA (1999)

Ivanov A.A., Bagryansky P.A., Lizunov A.A., Salomatin A.L., Zuev A.A. "Effect of limiter biasing on plasma MHD stability in GDT", paper IAEA-CN-94/EX/P5-12 at the Conference “Fusion Energy-2002,” Lyon, France, 2002. 
Kotelnikov I.A., Mirnov V.V., Nagornyj V.P., Ryutov D.D. "New results of gas-dynamic trap research.” In: "Plasma Physics and Controlled Fusion Research", v.2, p. 309, Vienna, IAEA (1985).

Kotelnikov I.A., Roslyakov G.V., Ryutov D.D., Stupakov G.V. "Stabilization of flute instability in axisymmetric mirror machines." In: "Plasma Physics and Controlled Fusion Research", v.2, p. 305, Vienna, IAEA (1987).

Kruglyakov E.P., Ivanov A.A., Tsidulko Yu.A. “Options for future development of mirror type $14 \mathrm{MeV}$ neutron source," Paper IAEA-CN-94/FT-P1-24 at the Conference “Fusion Energy-2002,” Lyon, France, 2002

Zukakishvili G.G., Ryzhkov V.N., Salukvadze R.G., Tikhanov E.K., Chkuaseli Z.D., Volosevich P.P., Galiguzova I.I., Dar'in N.A., Karpov V. Ya., Levanov E.I., "Plasma end loss confinement studies in a linear theta pimch with magnetic mirrors," In: "Plasma Physics and Controlled Fusion Research”, v.2, p. 359, Vienna, IAEA (1989).

There are also a couple dozen publications available in Russian

\section{A.3. Tandem mirror based neutron source references}

B. Badger, F. Arendt, H.M. Attaya, K. Audenaerde, H. Avci, et al., "TASKA: Tandem Spiegelmaschine Karlsruhe," University of Wisconsin Fusion Technology Institute Report UWFDM-500, Kernforschungszentrum Karlsruhe Report KfK-3311, Fusion Power Associates Report FPA-82-1 (1982). 
T.H. Batzer, R.H. Bulmer, J.N. Doggett, A.I. Goldner, J.A. Kerns, et al., “A Tandem Mirror Technology Demonstration Facility," Lawrence Livermore National Laboratory Report UCID-19328 (1983).

B. Badger, F. Arendt, E. Borie, M.L. Corradini, H.G. Dittrich, et al., "TASKA-M: A Low Cost, Near Term Tandem Mirror Device for Fusion Technology Testing," Fusion Power Associates Report FPA-83-7, Kernforschungszentrum Karlsruhe Report KfK-3680, University of Wisconsin Fusion Technology Institute Report UWFDM-600 (1983).

G.I Dimov, V.V. Zakaidakov, and M.E. Kishinevsky, “Thermonuclear Confinement with Twin Mirror Systems," Fiz. Plasmy 2, 326 (1976).

T.K. Fowler and B.G. Logan, “The Tandem Mirror Reactor," Comments on Plasma Physics and Controlled Fusion 2, 167 (1977). 